\title{
Isolation and Total Synthesis of Mabuniamide, a Lipopeptide from an Okeania sp. Marine Cyanobacterium
}

Kaori Ozaki, ${ }^{\dagger}$ Arihiro Iwasaki,${ }^{\ddagger}$ Dai Sezawa,${ }^{\ddagger}$ Haruka Fujimura,${ }^{\ddagger}$ Tomoyoshi Nozaki,${ }^{\S}$ Yumiko Saito-

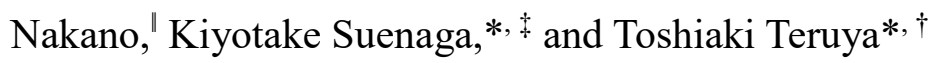

'Graduate School of Science, University of the Ryukyus, 1 Senbaru, Nishihara, Okinawa 903-0213, Japan Department of Chemistry, Faculty of Science and Technology, Keio University, 3-14-1 Hiyoshi, Kohoku-ku, Yokohama, Kanagawa 223-8522, Japan

${ }^{\S}$ Department of Biomedical Chemistry, Graduate School of Medicine, The University of Tokyo, 7-3-1 Hongo, Bunkyo-ku, Tokyo 113-0033, Japan

'Department of Parasitology, National Institute of Infectious Diseases, 1-23-1 Toyama, Shinjuku-ku, Tokyo 1628640, Japan

\section{Contents}

Phylogenetic tree

NMR spectrum of mabuniamide (1) in $\mathrm{CDCl}_{3}$

Spectral data of all synthetic compounds

MS/MS analyses of mabuniamide (1)

\section{Page Number}

S2

S3

S9

S41 


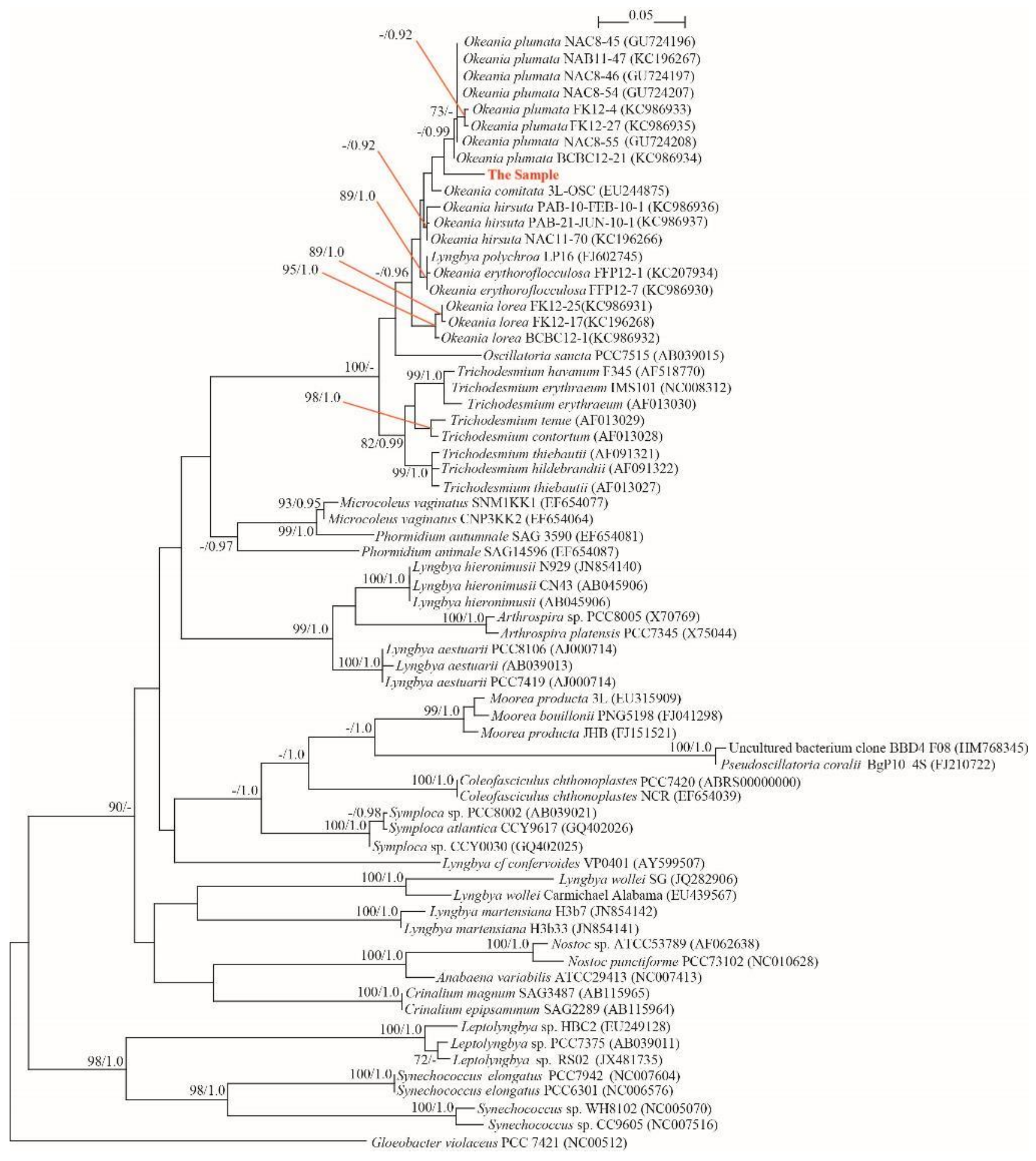

Figure S1. Phylogenetic tree inferred from 16S rDNA sequences using the ML method. The phylogeny is rooted with Gloeobacter violaceus PCC 7421. The numbers at the nodes indicate bootstrap values (values $<70 \%$ are not shown) and posterior probability (values $<0.9$ are not shown) for the $\quad$ ML/Bayesian inference. 


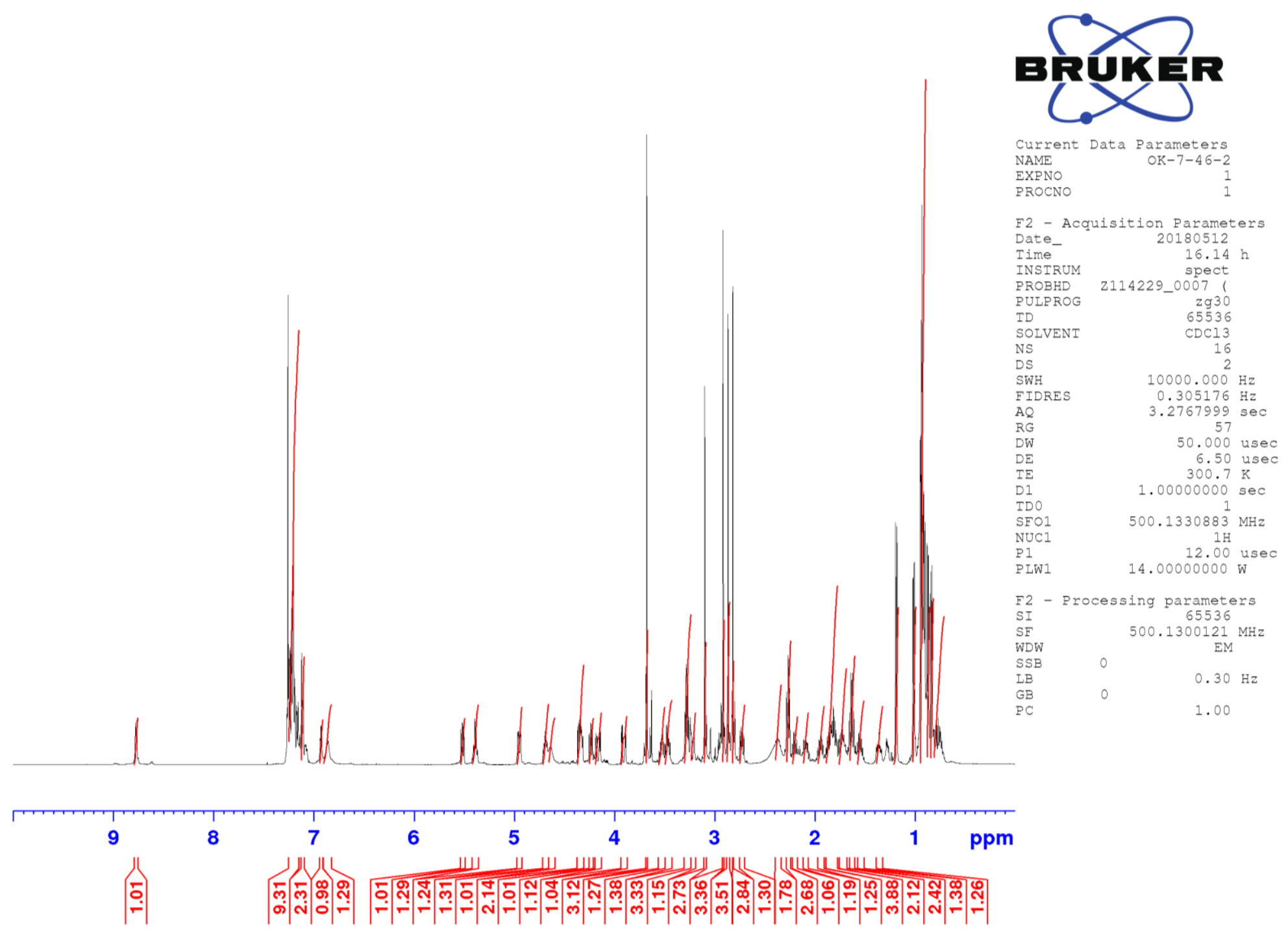

Figure S2. ${ }^{1} \mathrm{H}$ NMR spectrum of mabuniamide (1) in $\mathrm{CDCl}_{3}(500 \mathrm{MHz})$ 


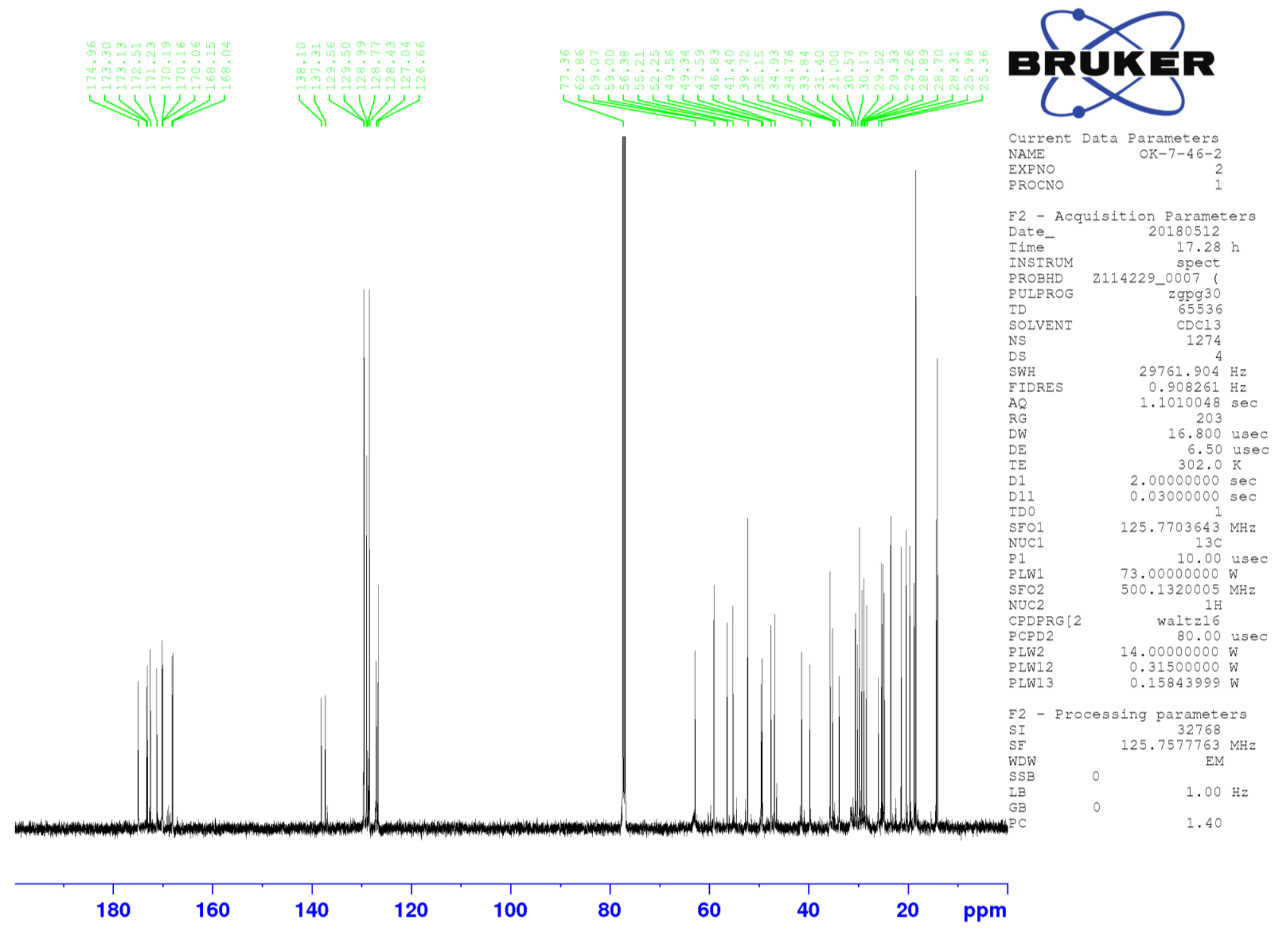

Figure S3. ${ }^{13} \mathrm{C}$ NMR spectrum of mabuniamide (1) in $\mathrm{CDCl}_{3}(125 \mathrm{MHz})$ 


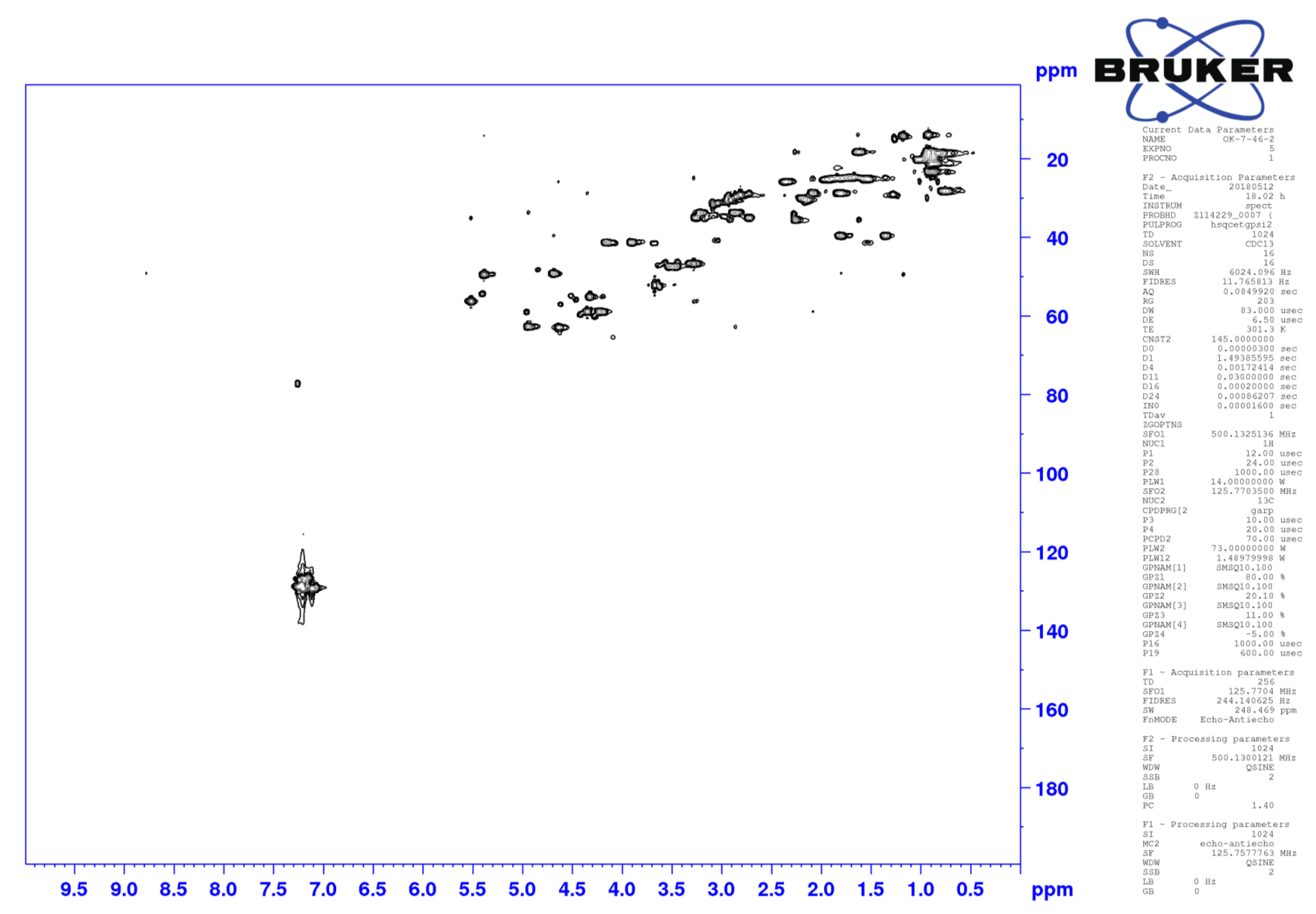

Figure S4. HSQC spectrum of mabuniamide (1) in $\mathrm{CDCl}_{3}(500 \mathrm{MHz})$ 


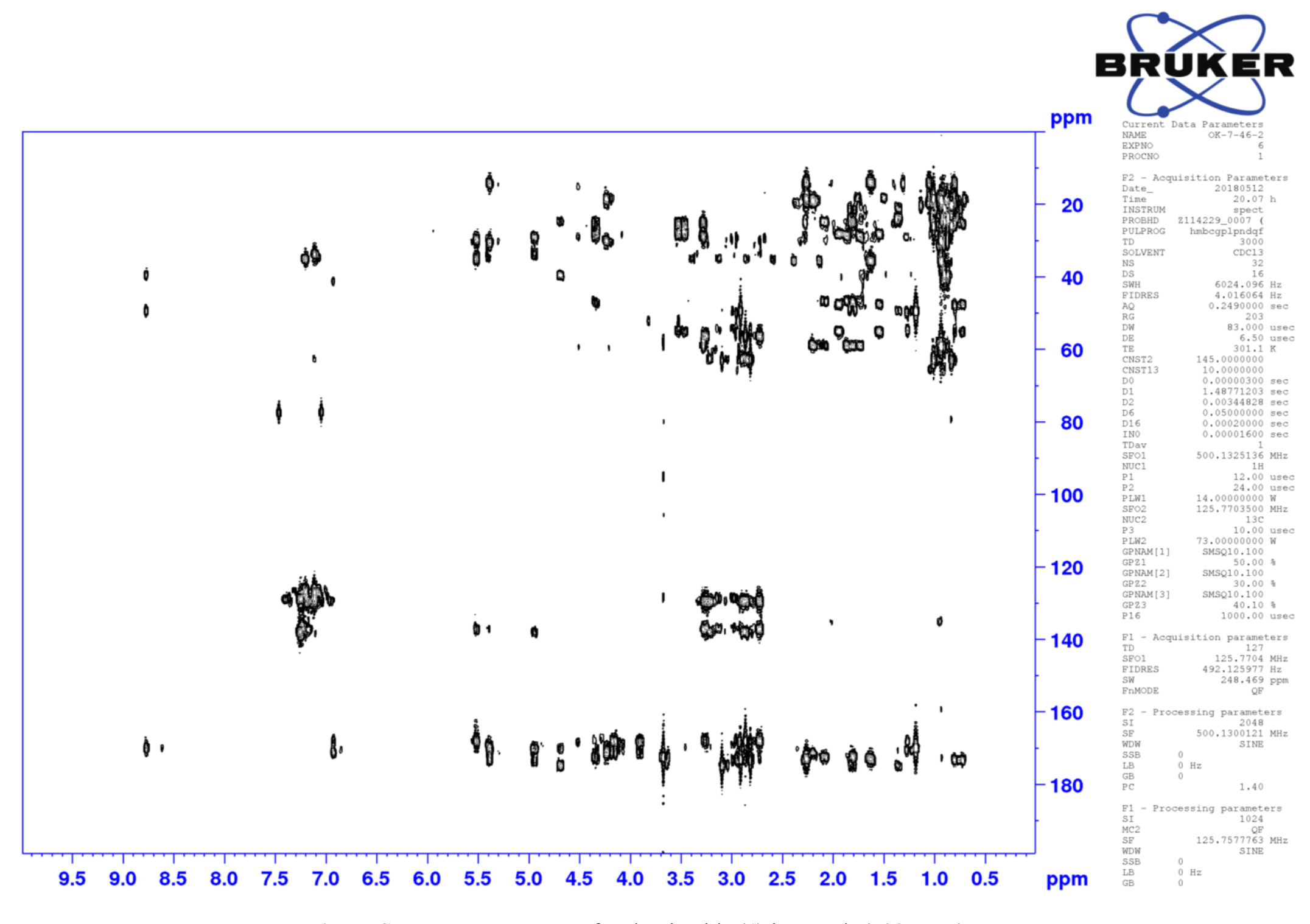

Figure S5. $\mathrm{HMBC}$ spectrum of mabuniamide (1) in $\mathrm{CDCl}_{3}(500 \mathrm{MHz})$ 

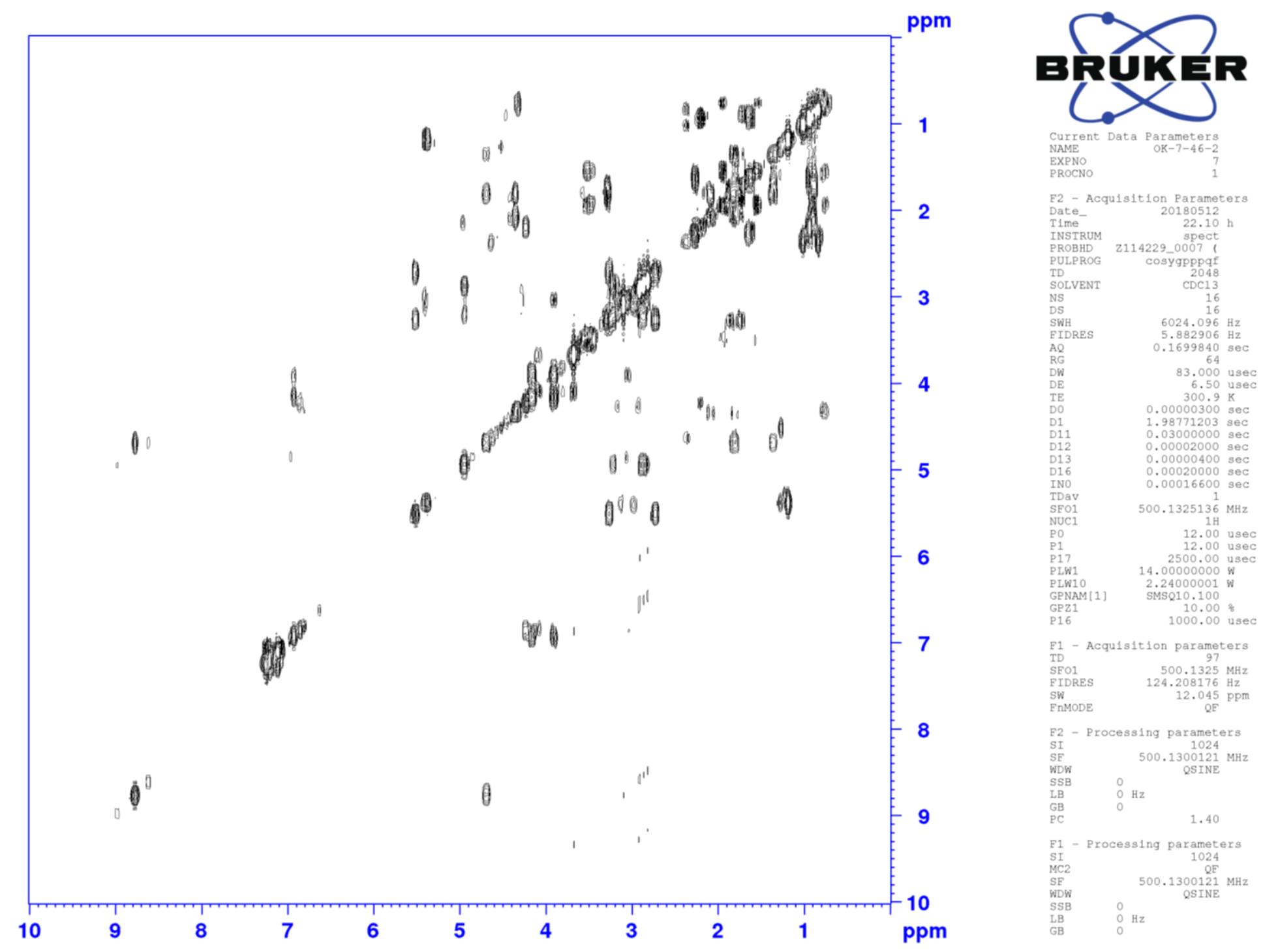

Figure S6. COSY spectrum of mabuniamide (1) in $\mathrm{CDCl}_{3}(500 \mathrm{MHz})$ 


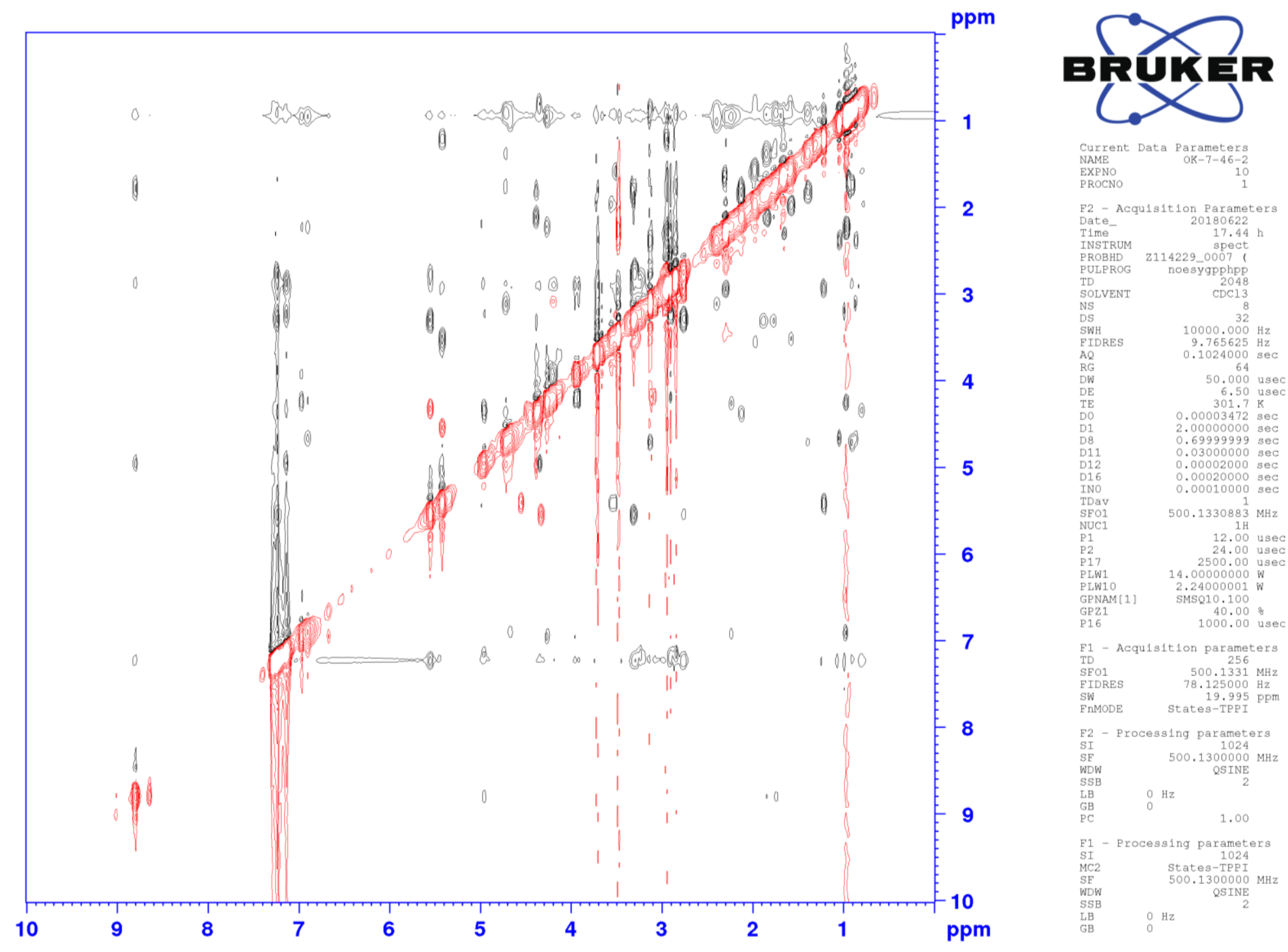

Figure S7. NOESY spectrum of mabuniamide (1) in $\mathrm{CDCl}_{3}(500 \mathrm{MHz})$ 


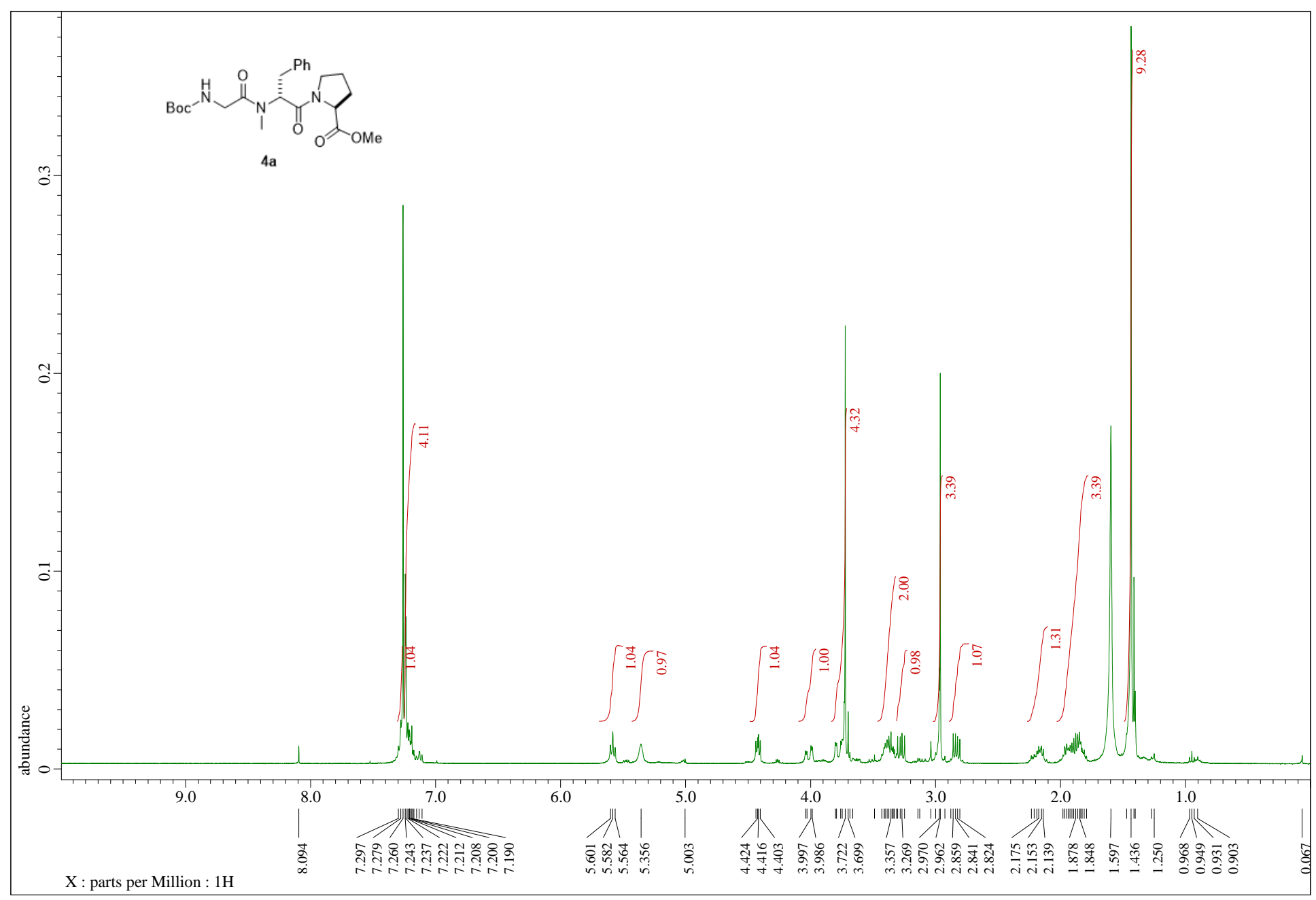

Figure S8. ${ }^{1} \mathrm{H}$ NMR spectrum of tripeptide 4 a in $\mathrm{CDCl}_{3}(400 \mathrm{MHz})$ 


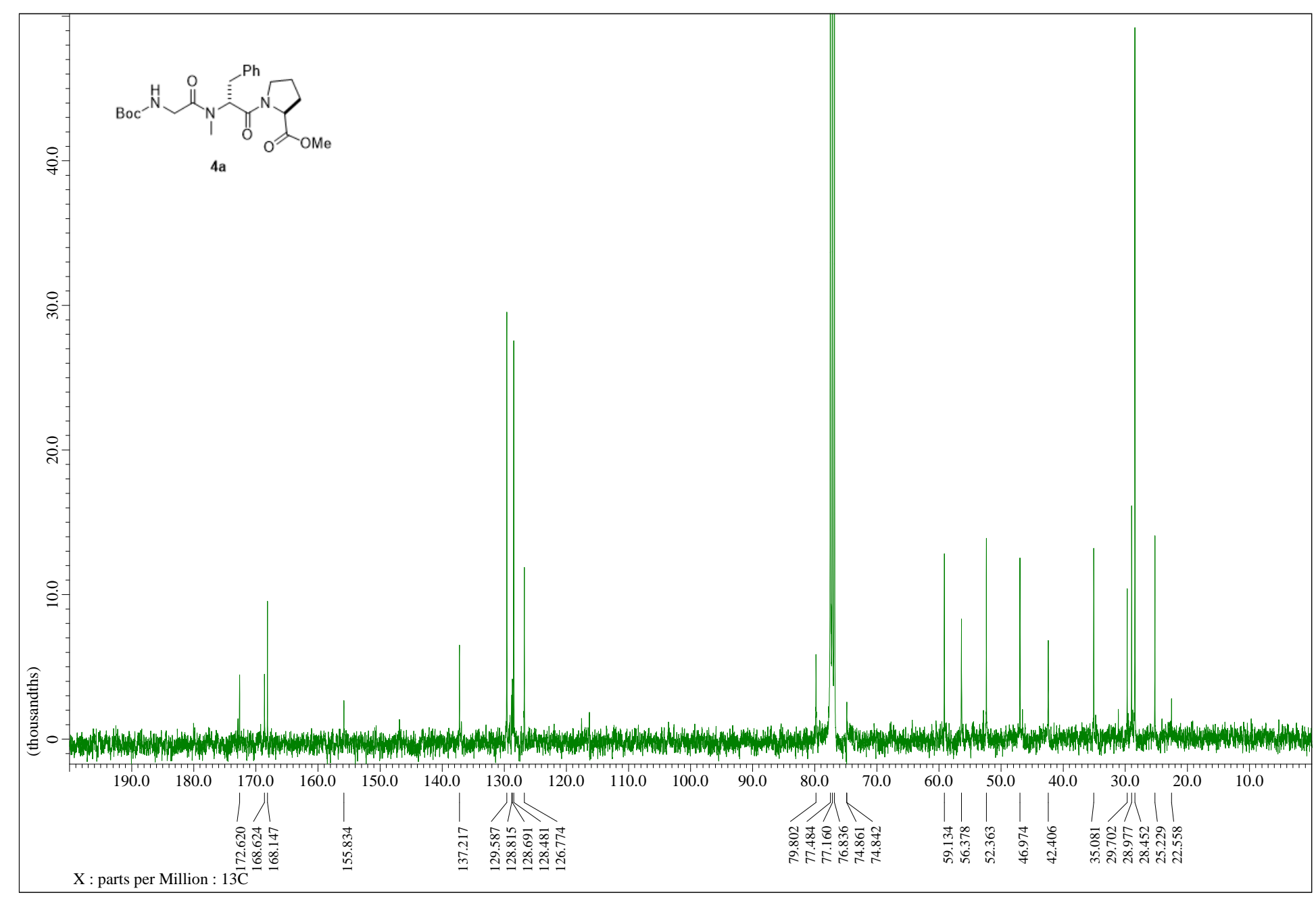

Figure S9. ${ }^{13} \mathrm{C}$ NMR spectrum of tripeptide $4 \mathbf{a}$ in $\mathrm{CDCl}_{3}(100 \mathrm{MHz})$ 


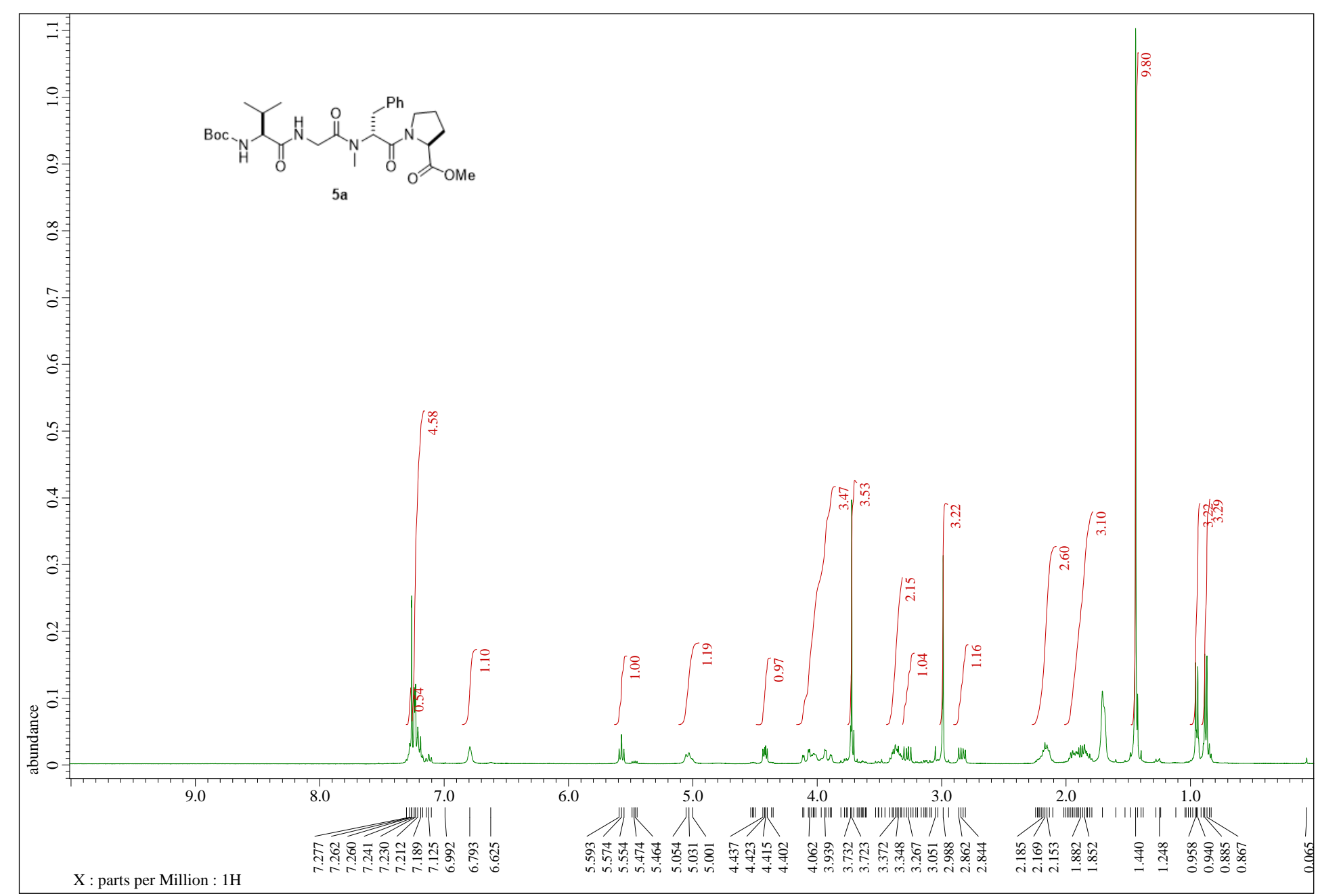

Figure S10. ${ }^{1} \mathrm{H}$ NMR spectrum of tetrapeptide 5a in $\mathrm{CDCl}_{3}(400 \mathrm{MHz})$ 


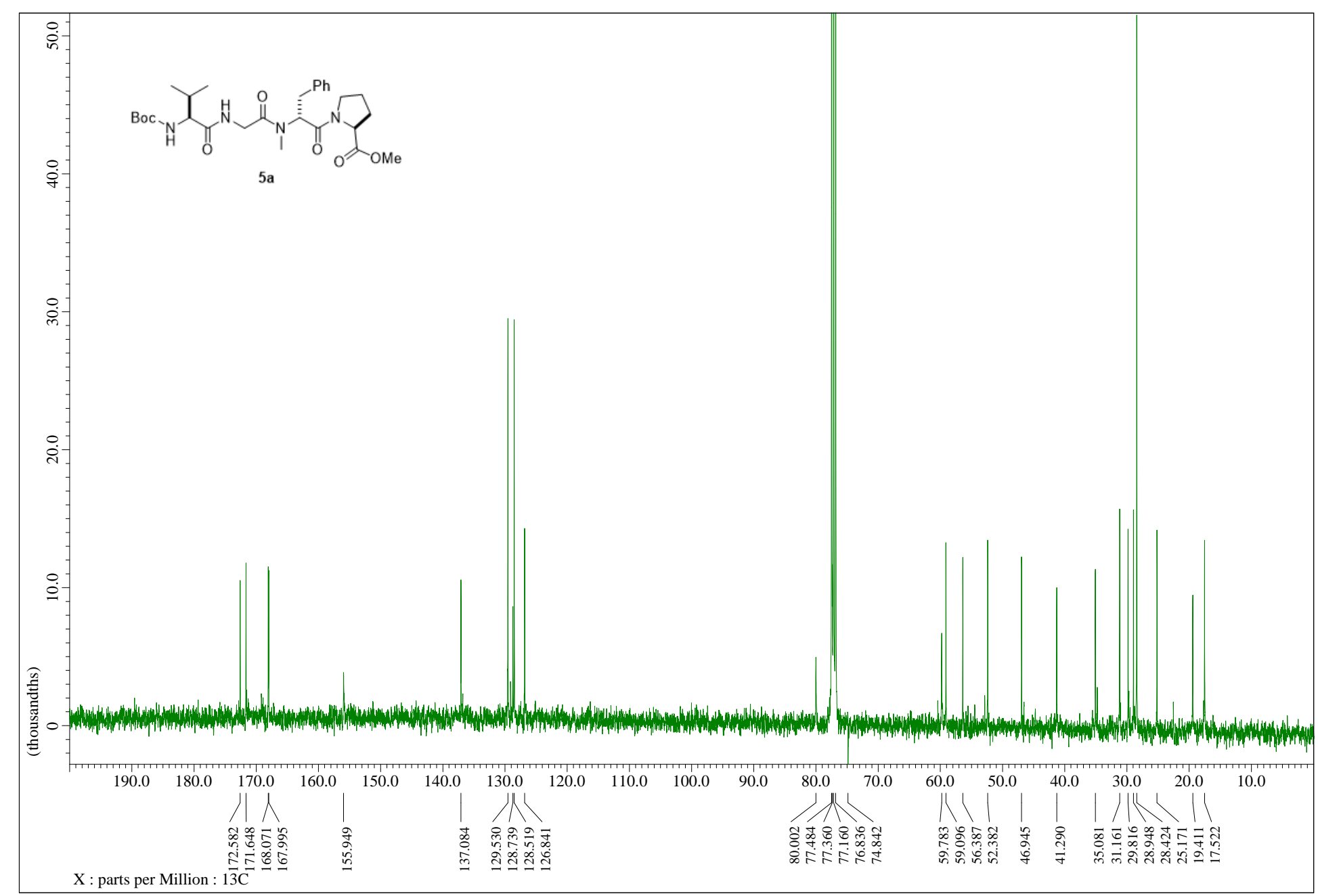

Figure S11. ${ }^{13} \mathrm{C}$ NMR spectrum of tetrapeptide $5 \mathbf{a}$ in $\mathrm{CDCl}_{3}(100 \mathrm{MHz})$ 


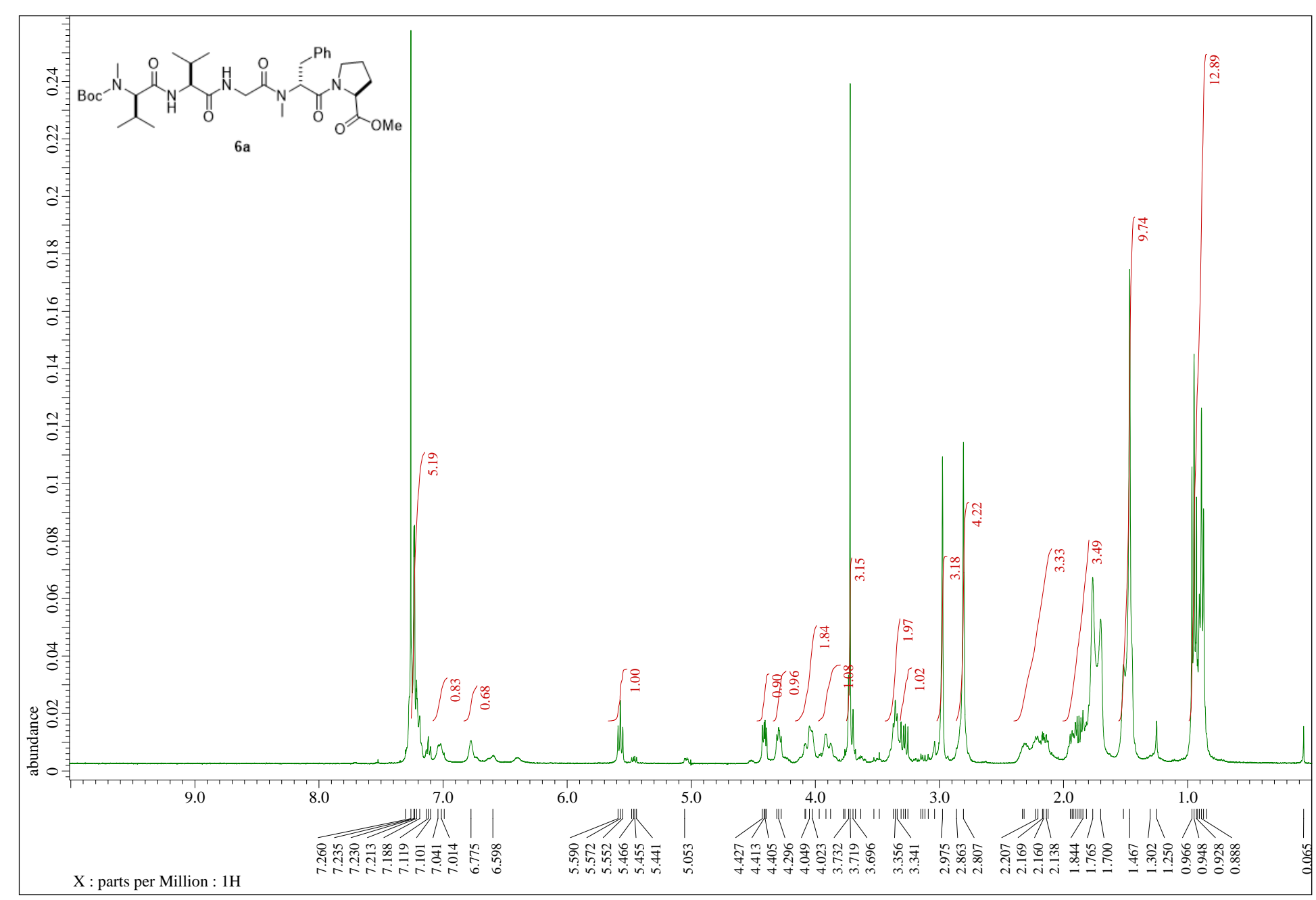

Figure S12. ${ }^{1} \mathrm{H}$ NMR spectrum of pentapeptide $\mathbf{6 a}$ in $\mathrm{CDCl}_{3}(400 \mathrm{MHz})$ 


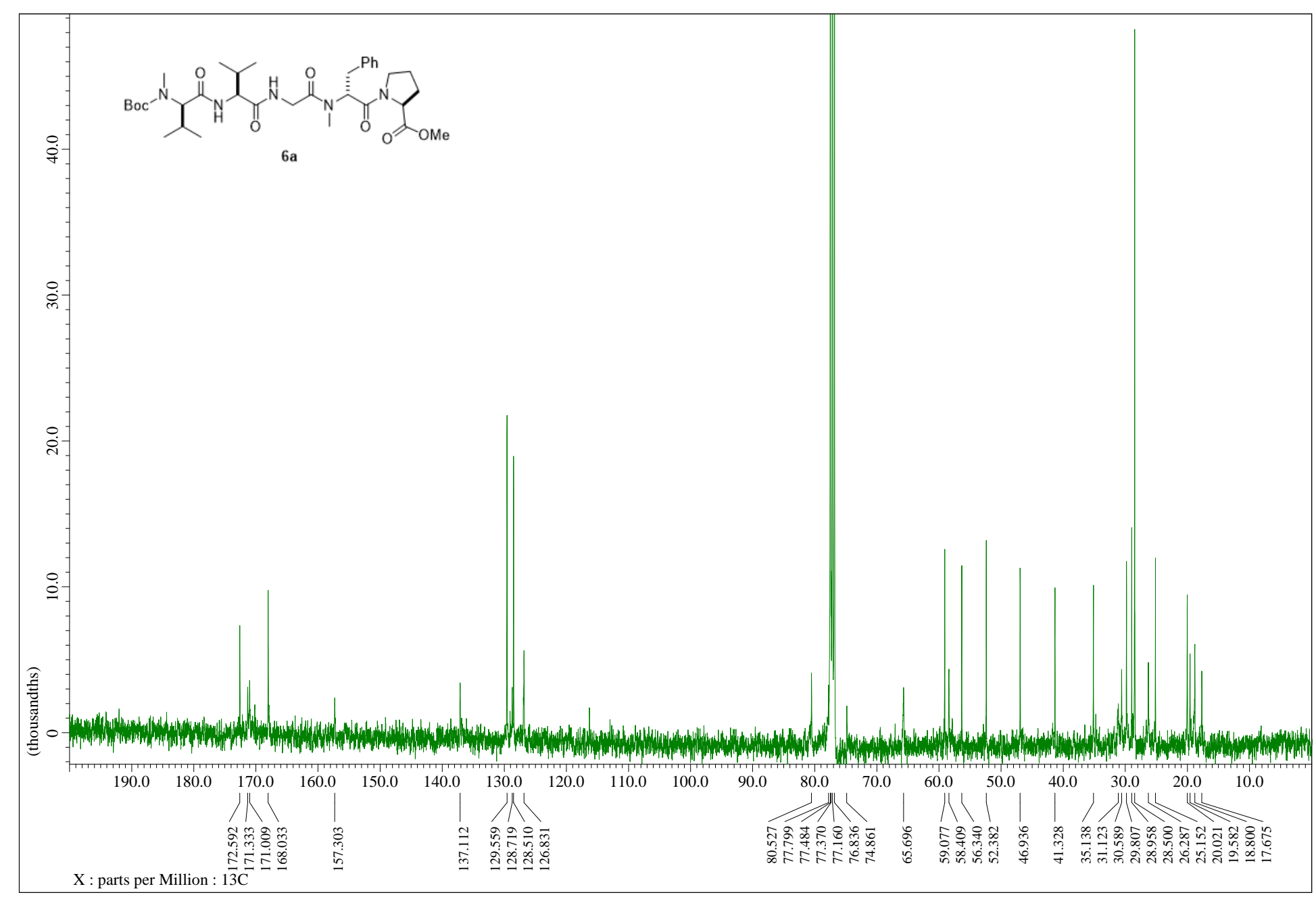

Figure S13. ${ }^{13} \mathrm{C}$ NMR spectrum of pentapeptide 6a in $\mathrm{CDCl}_{3}(100 \mathrm{MHz})$ 


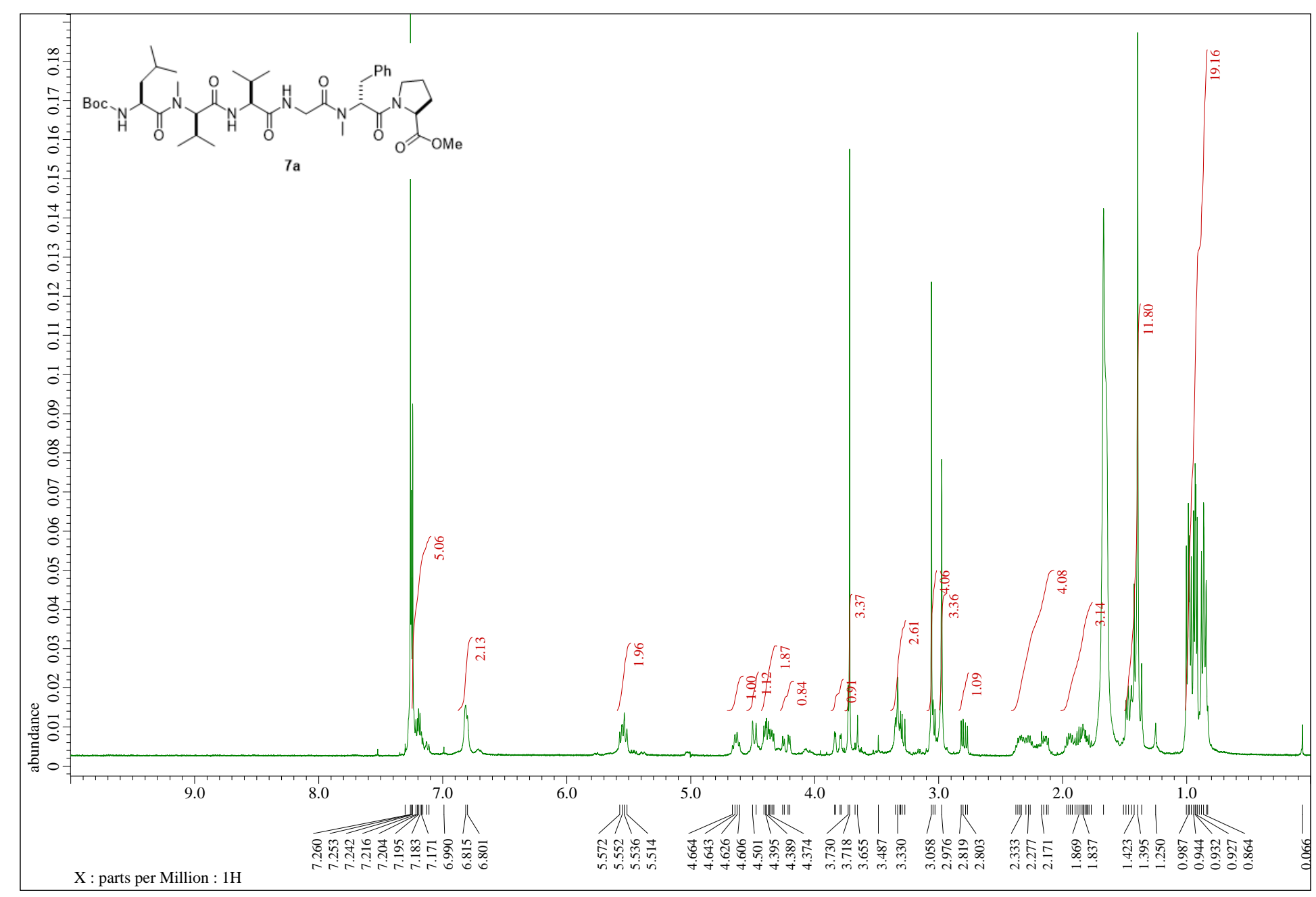

Figure S14. ${ }^{1} \mathrm{H}$ NMR spectrum of hexapeptide $7 \mathbf{a}$ in $\mathrm{CDCl}_{3}(400 \mathrm{MHz})$ 


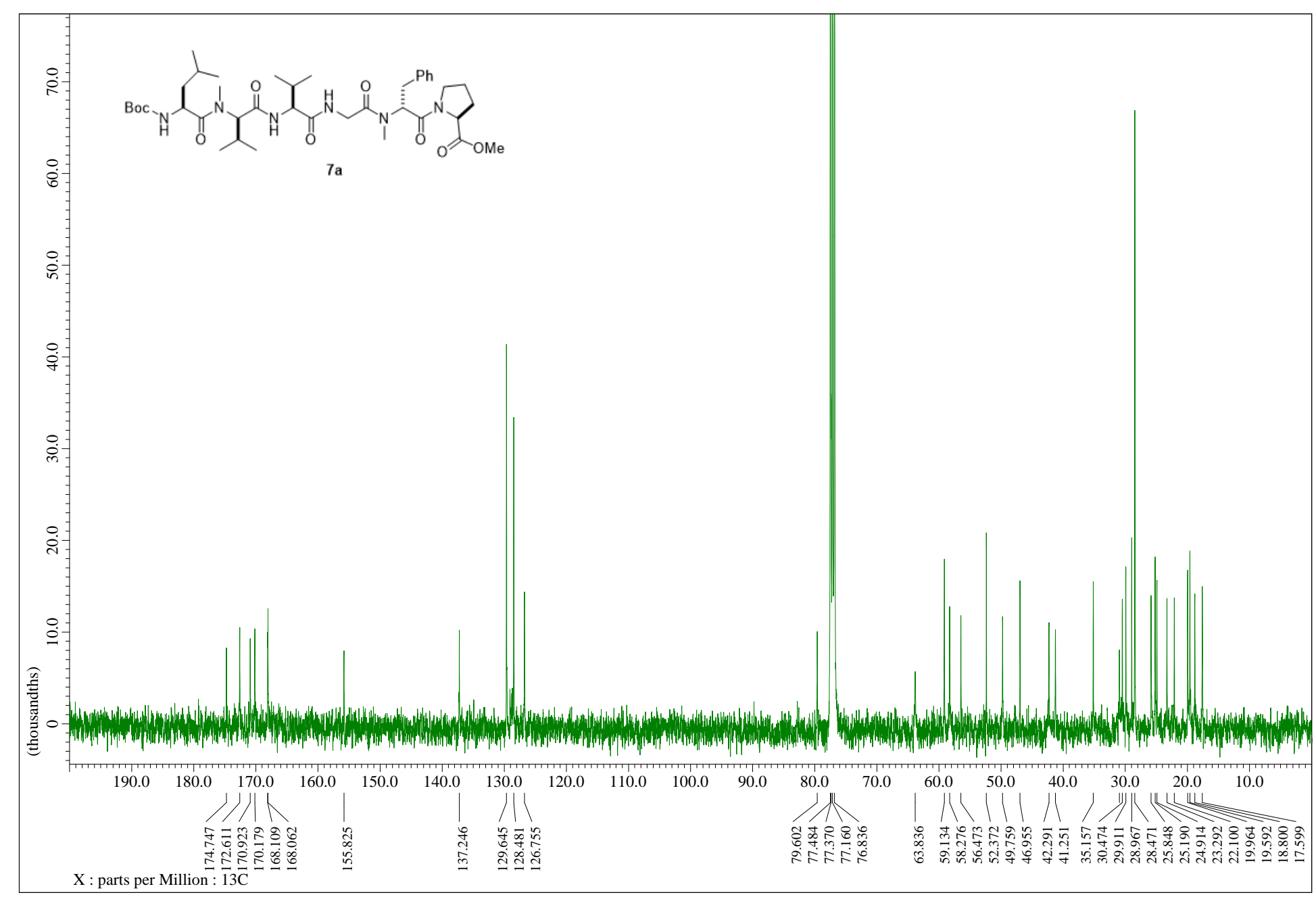

Figure S15. ${ }^{13} \mathrm{C}$ NMR spectrum of hexapeptide $7 \mathbf{a}$ in $\mathrm{CDCl}_{3}(100 \mathrm{MHz})$ 


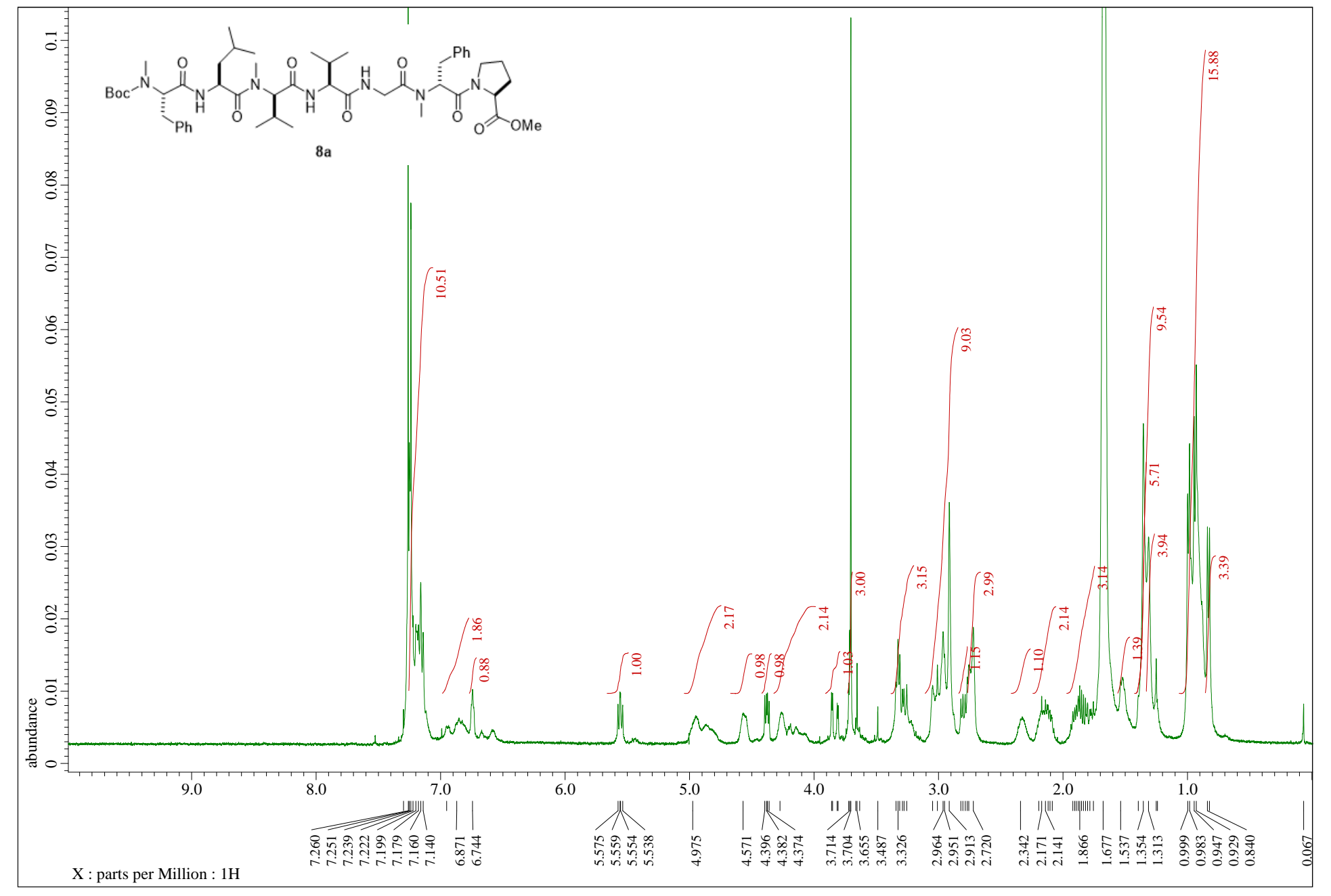

Figure S16. ${ }^{1} \mathrm{H}$ NMR spectrum of heptapeptide $8 \mathbf{a}$ in $\mathrm{CDCl}_{3}(400 \mathrm{MHz})$ 


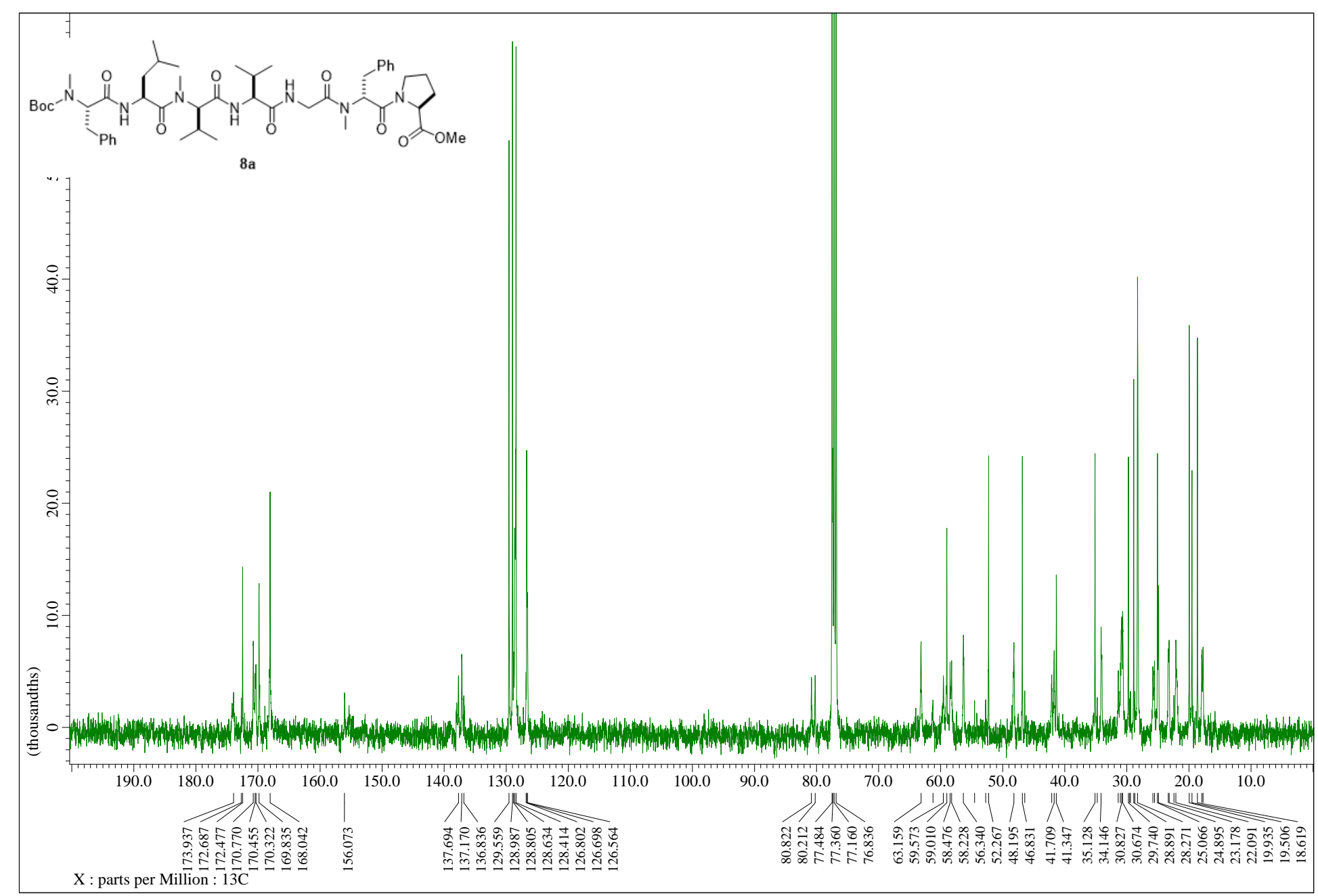

Figure S17. ${ }^{13} \mathrm{C}$ NMR spectrum of heptapeptide 8a in $\mathrm{CDCl}_{3}(100 \mathrm{MHz})$ 


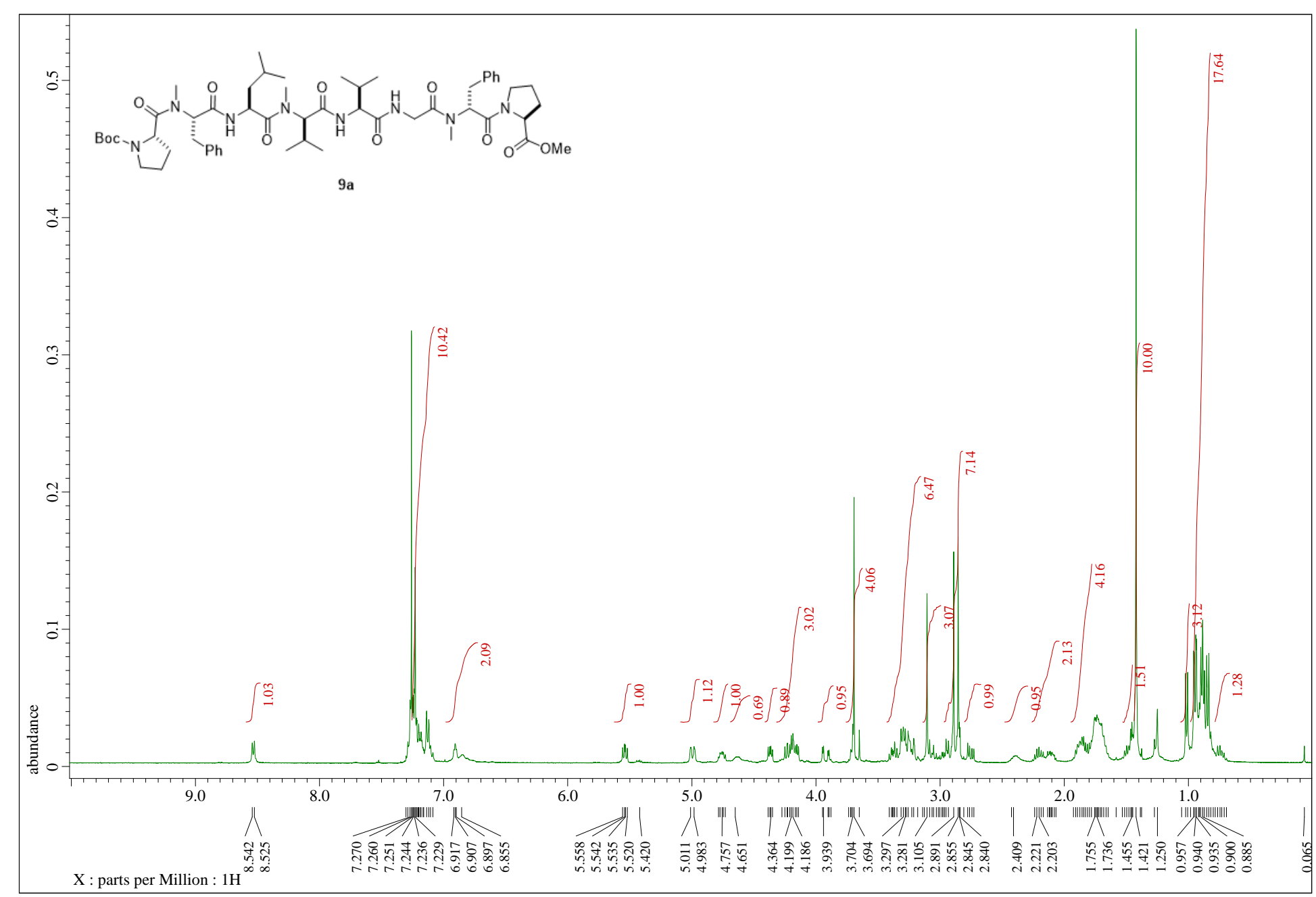

Figure S18. ${ }^{1} \mathrm{H}$ NMR spectrum of octapeptide 9a in $\mathrm{CDCl}_{3}(400 \mathrm{MHz})$ 


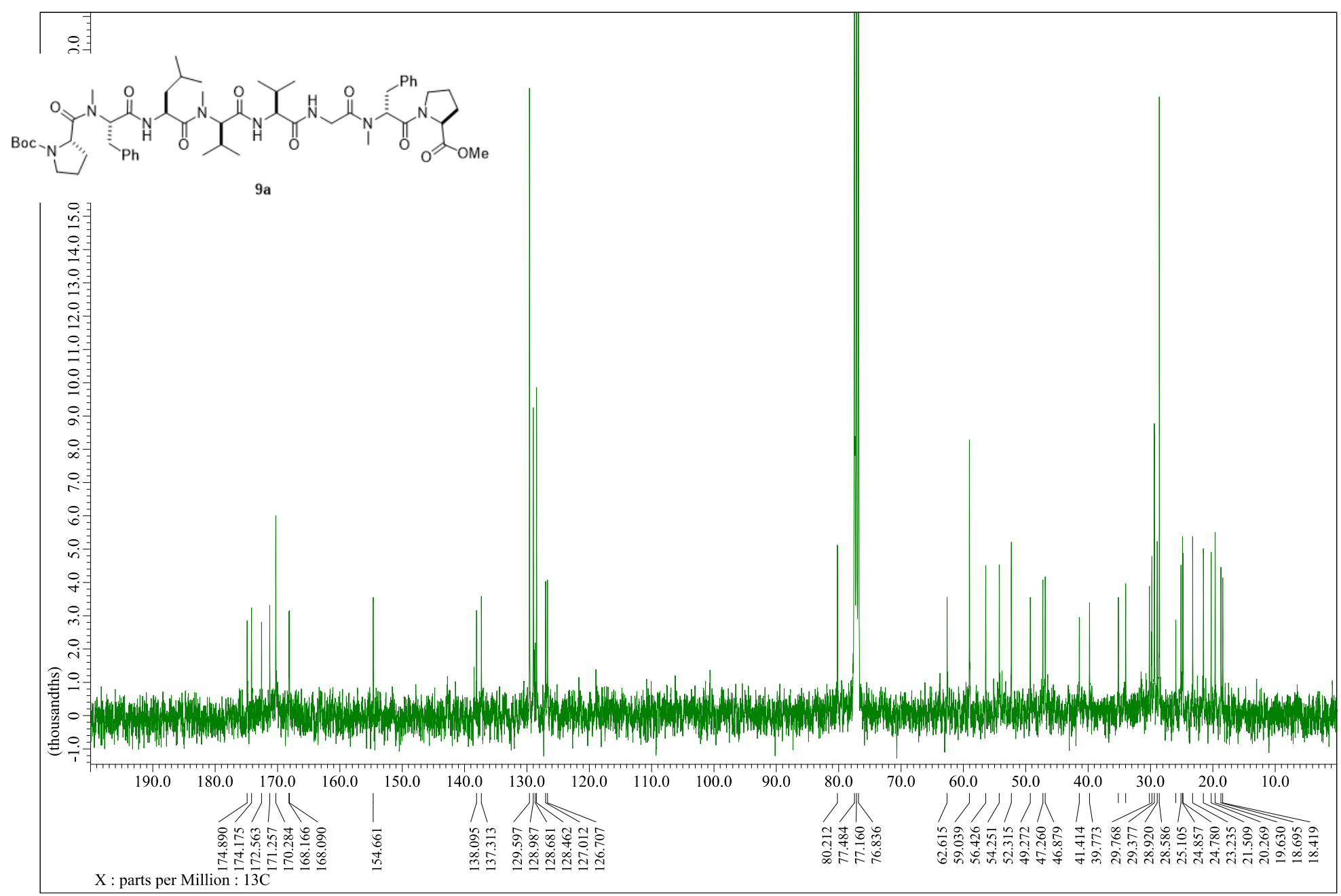

Figure S19. ${ }^{13} \mathrm{C}$ NMR spectrum of octapeptide 9a in $\mathrm{CDCl}_{3}(100 \mathrm{MHz})$ 


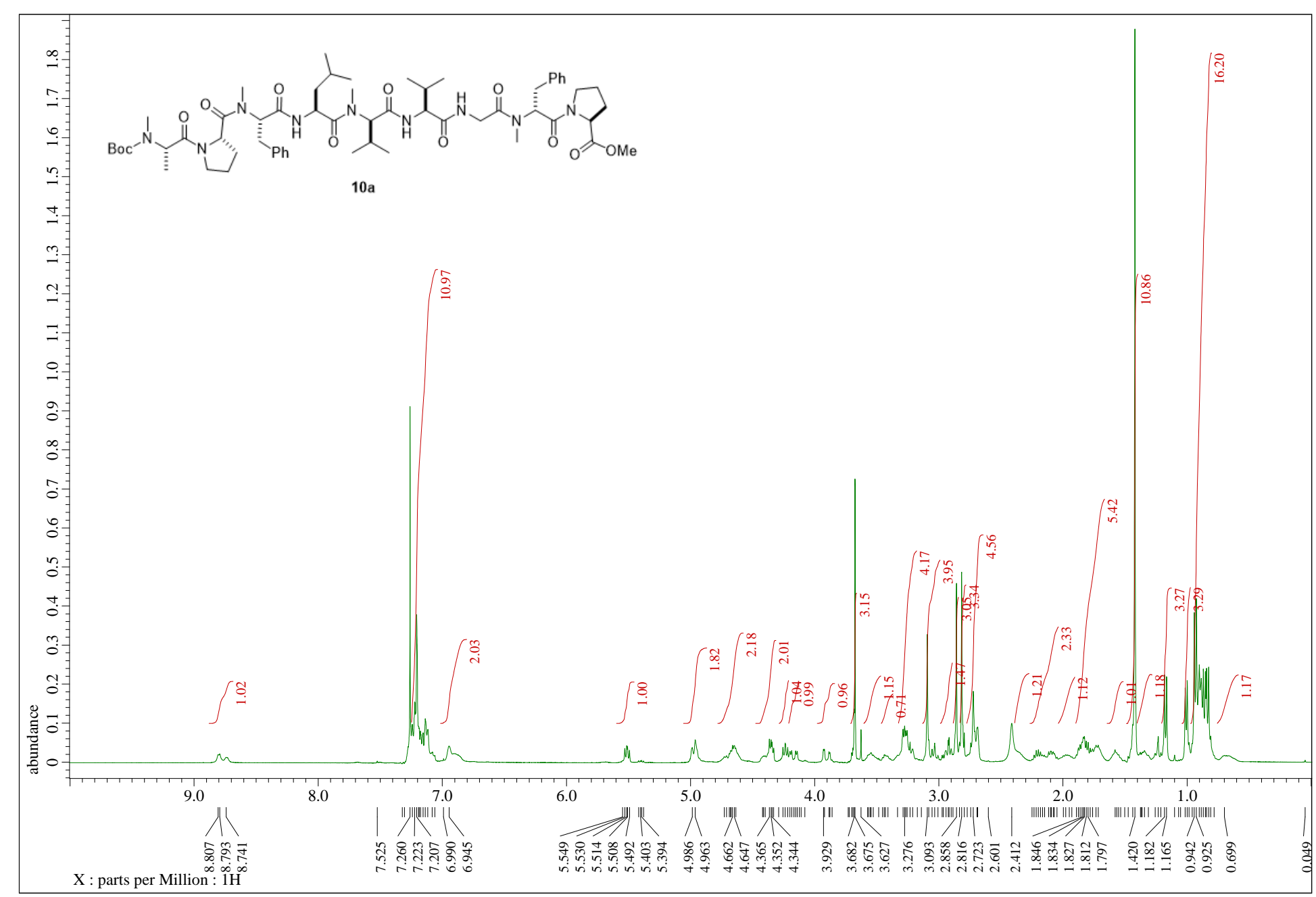

Figure S20. ${ }^{1} \mathrm{H}$ NMR spectrum of nonapeptide 10a in $\mathrm{CDCl}_{3}(400 \mathrm{MHz})$ 


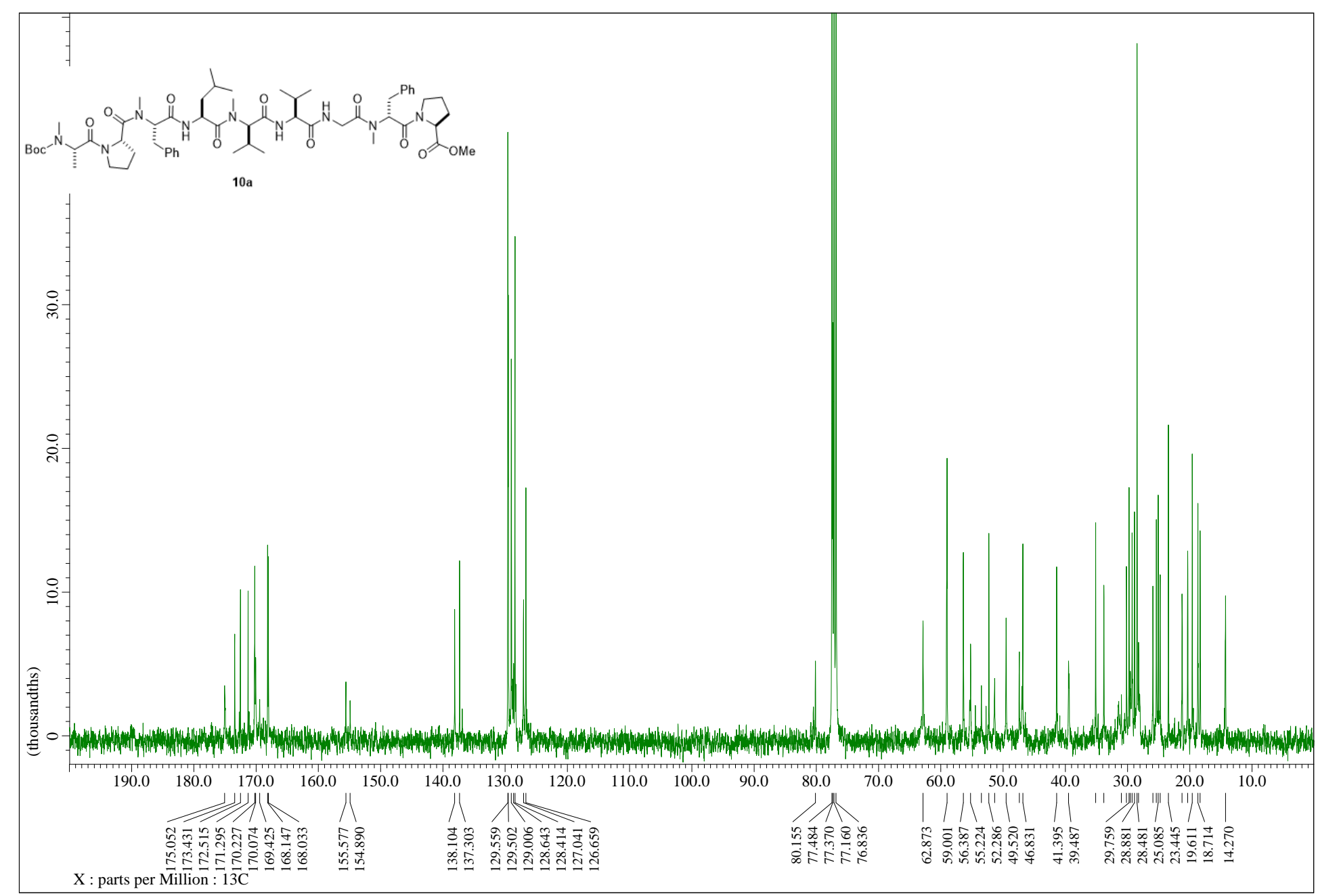

Figure S21. ${ }^{13} \mathrm{C}$ NMR spectrum of nonapeptide 10a in $\mathrm{CDCl}_{3}(100 \mathrm{MHz})$ 


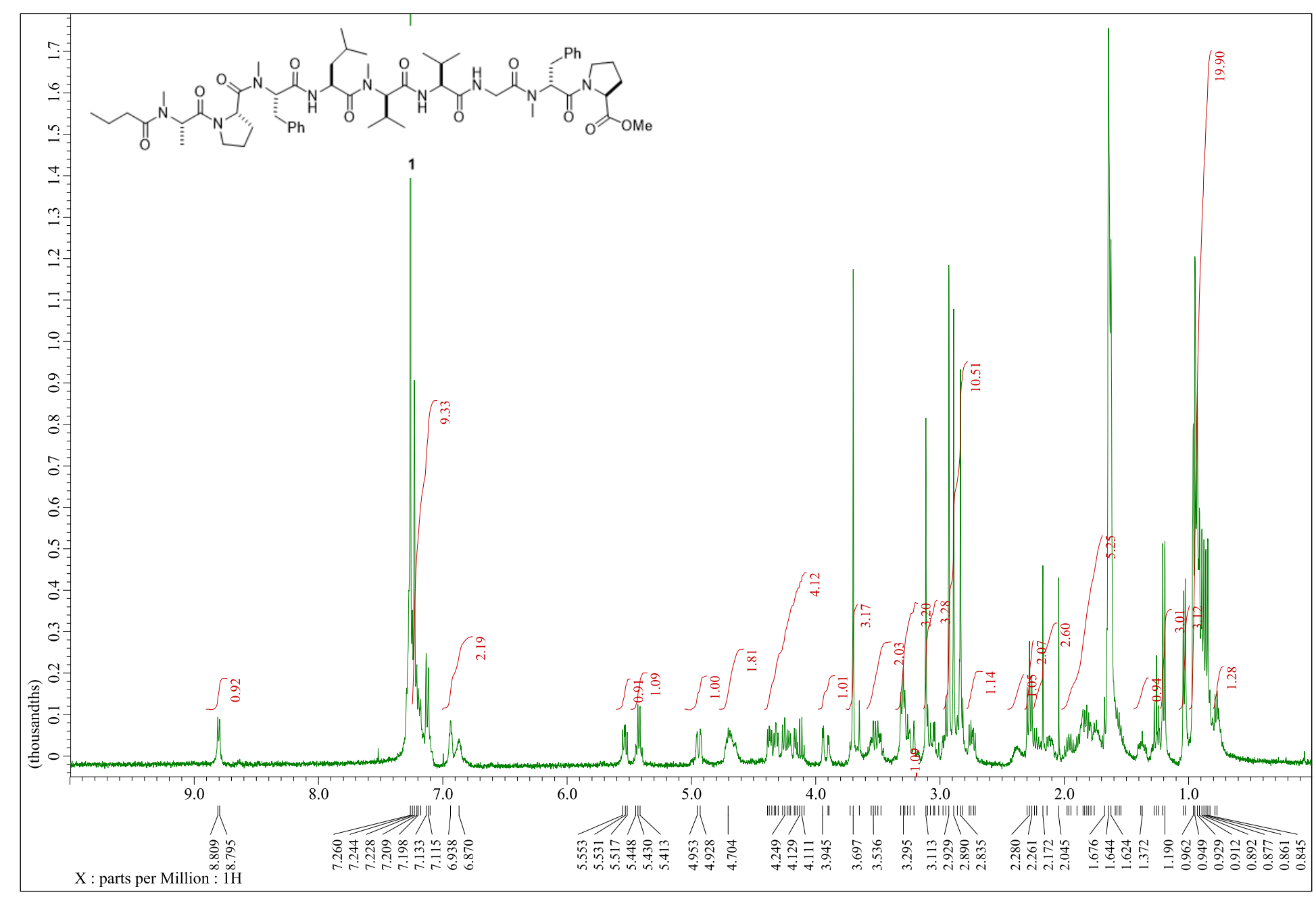

Figure S22. ${ }^{1} \mathrm{H}$ NMR spectrum of synthetic mabuniamide (1) in $\mathrm{CDCl}_{3}(400 \mathrm{MHz})$ 


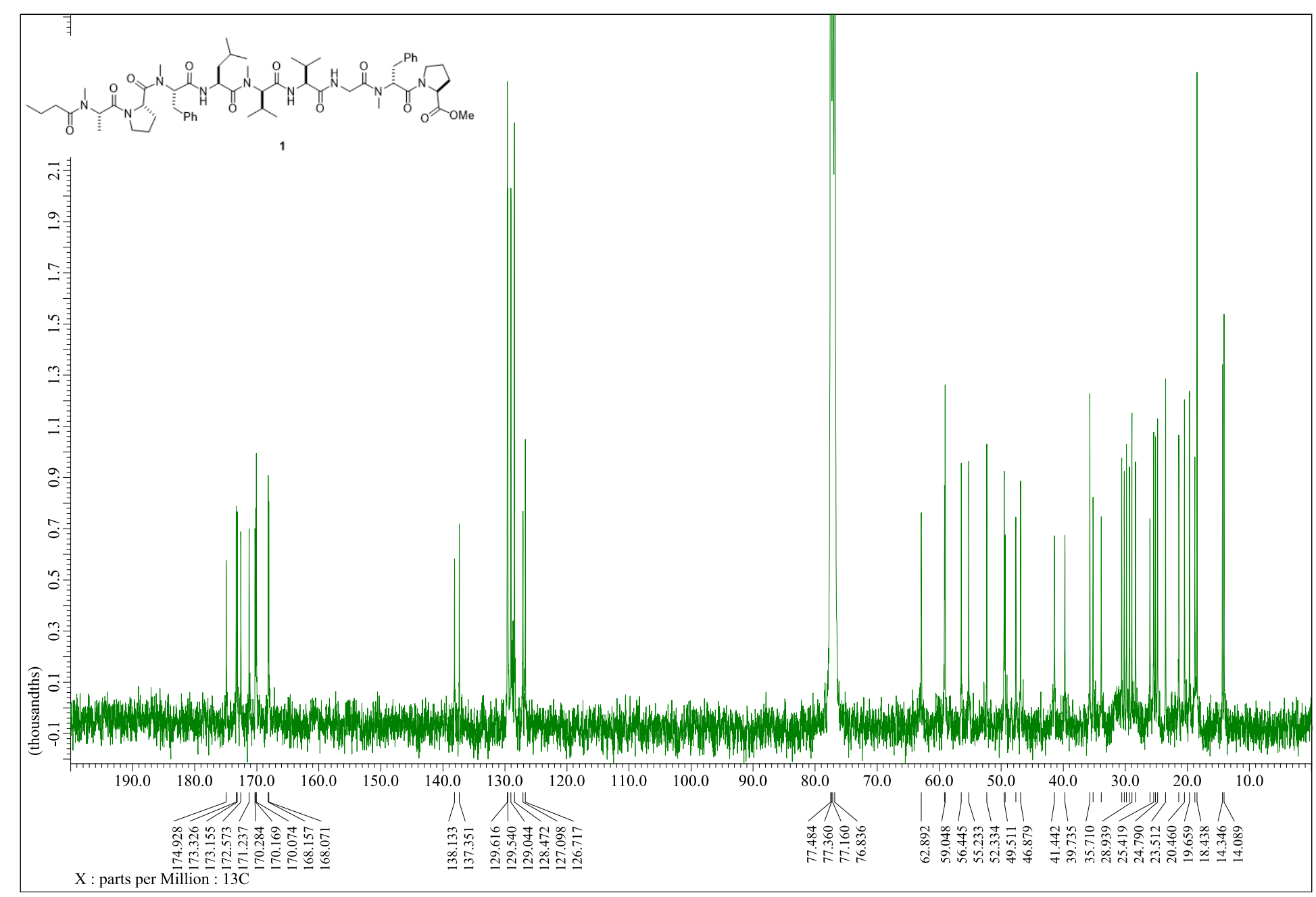

Figure S23. ${ }^{13} \mathrm{C}$ NMR spectrum of synthetic mabuniamide (1) in $\mathrm{CDCl}_{3}(100 \mathrm{MHz})$ 


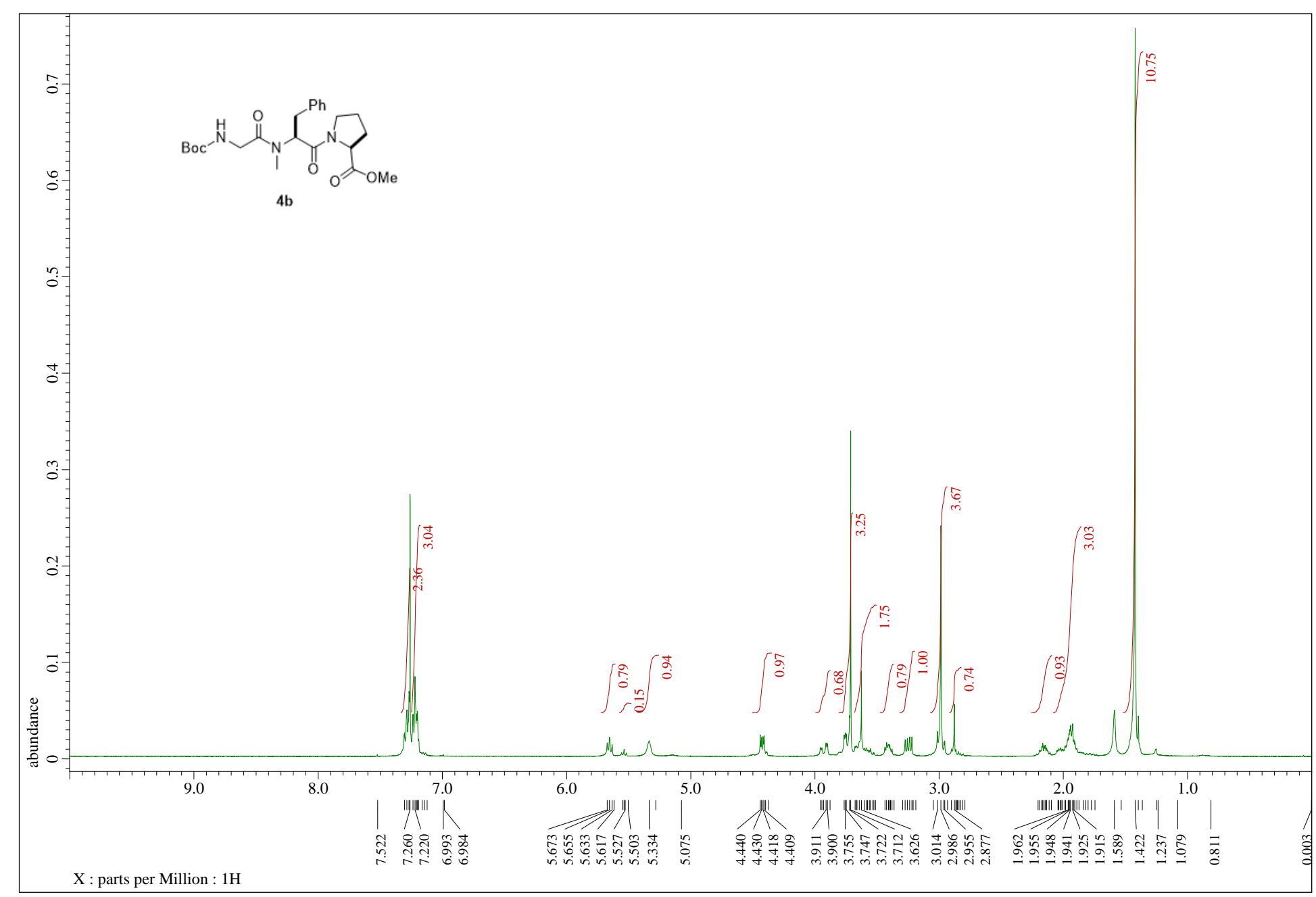

Figure S24. ${ }^{1} \mathrm{H}$ NMR spectrum of tripeptide $\mathbf{4 b}$ in $\mathrm{CDCl}_{3}(400 \mathrm{MHz})$ 


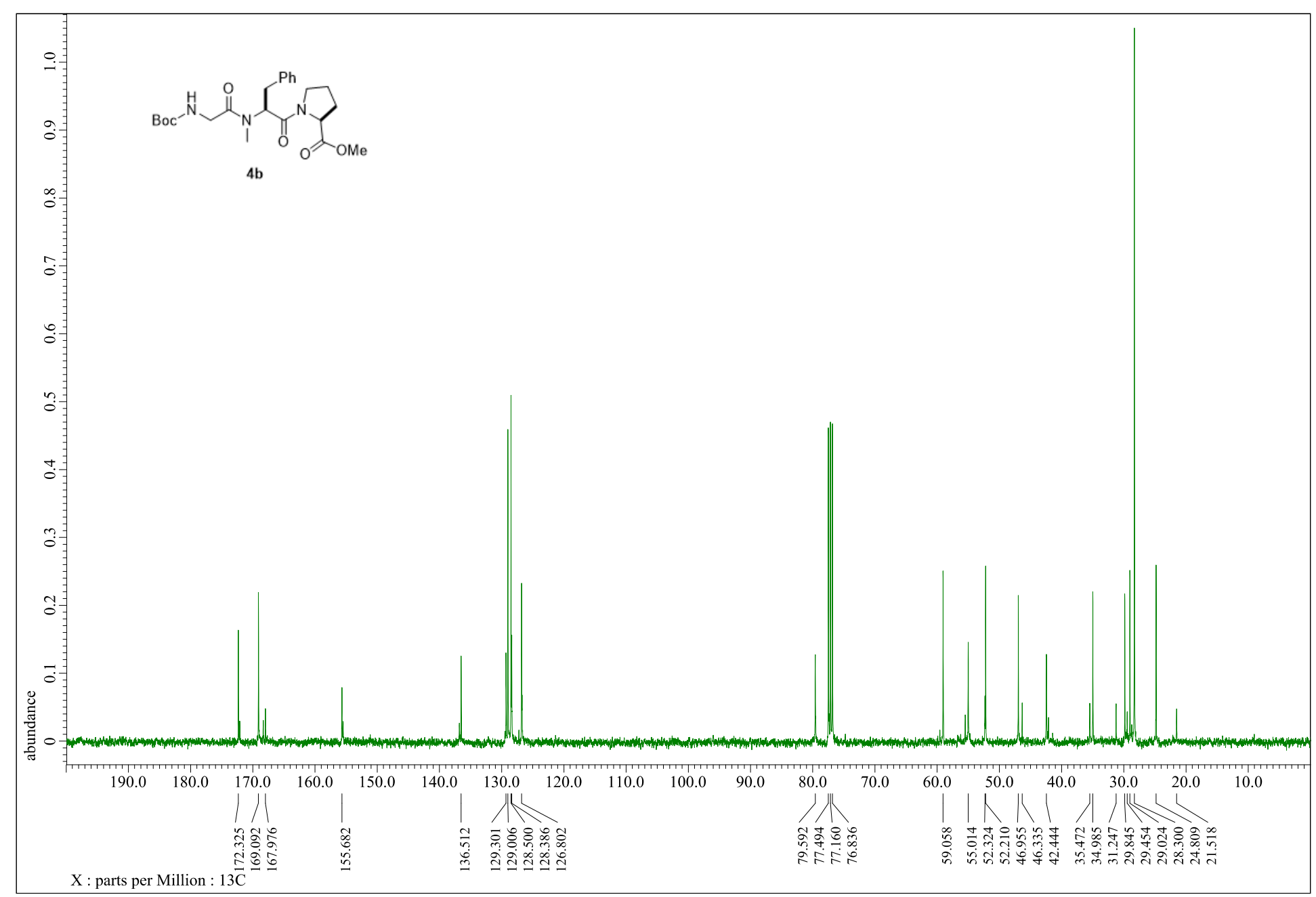

Figure S25. ${ }^{13} \mathrm{C}$ NMR spectrum of tripeptide $4 \mathbf{b}$ in $\mathrm{CDCl}_{3}(100 \mathrm{MHz})$ 


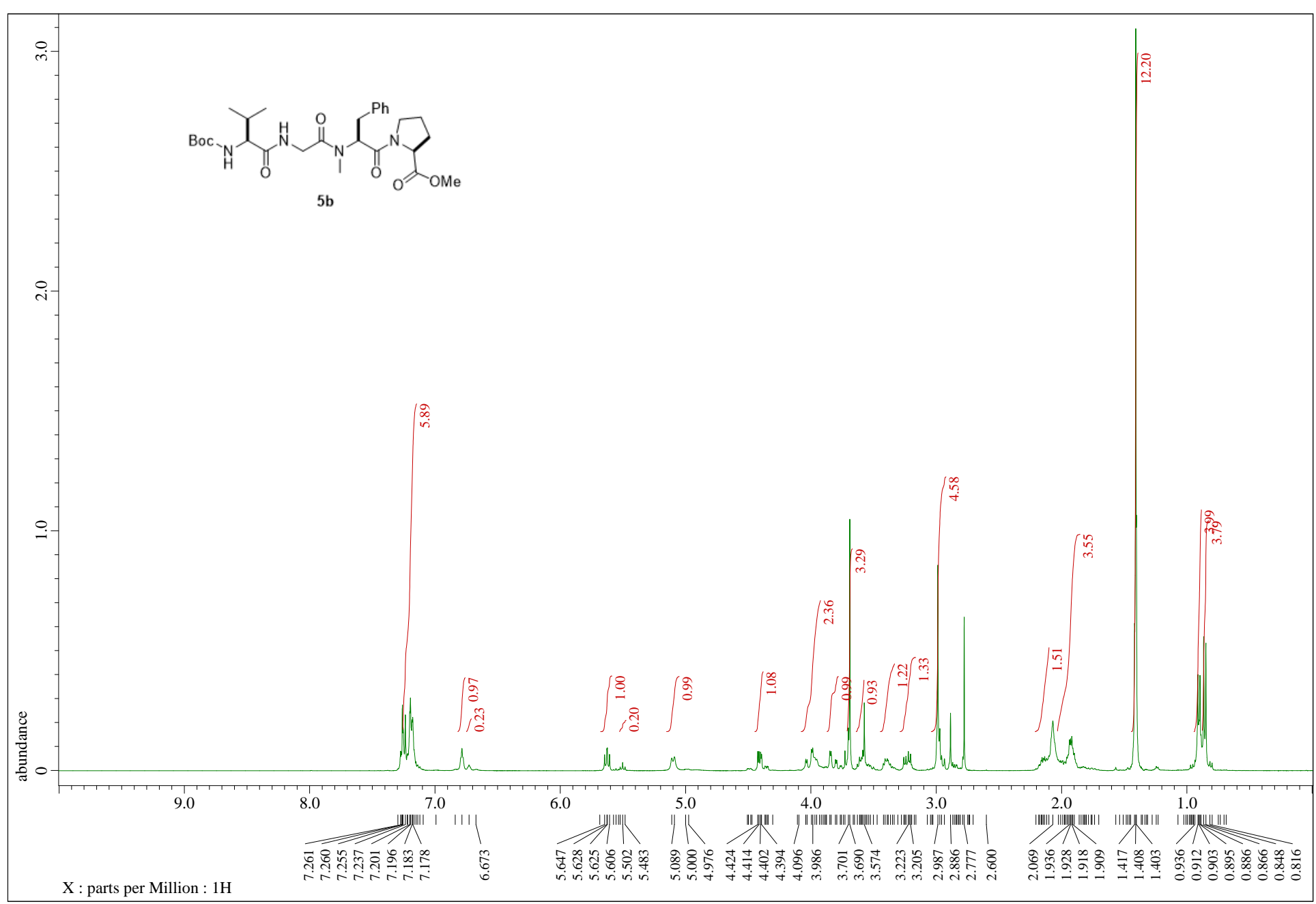

Figure S26. ${ }^{1} \mathrm{H}$ NMR spectrum of tetrapeptide $\mathbf{5 b}$ in $\mathrm{CDCl}_{3}(400 \mathrm{MHz})$ 


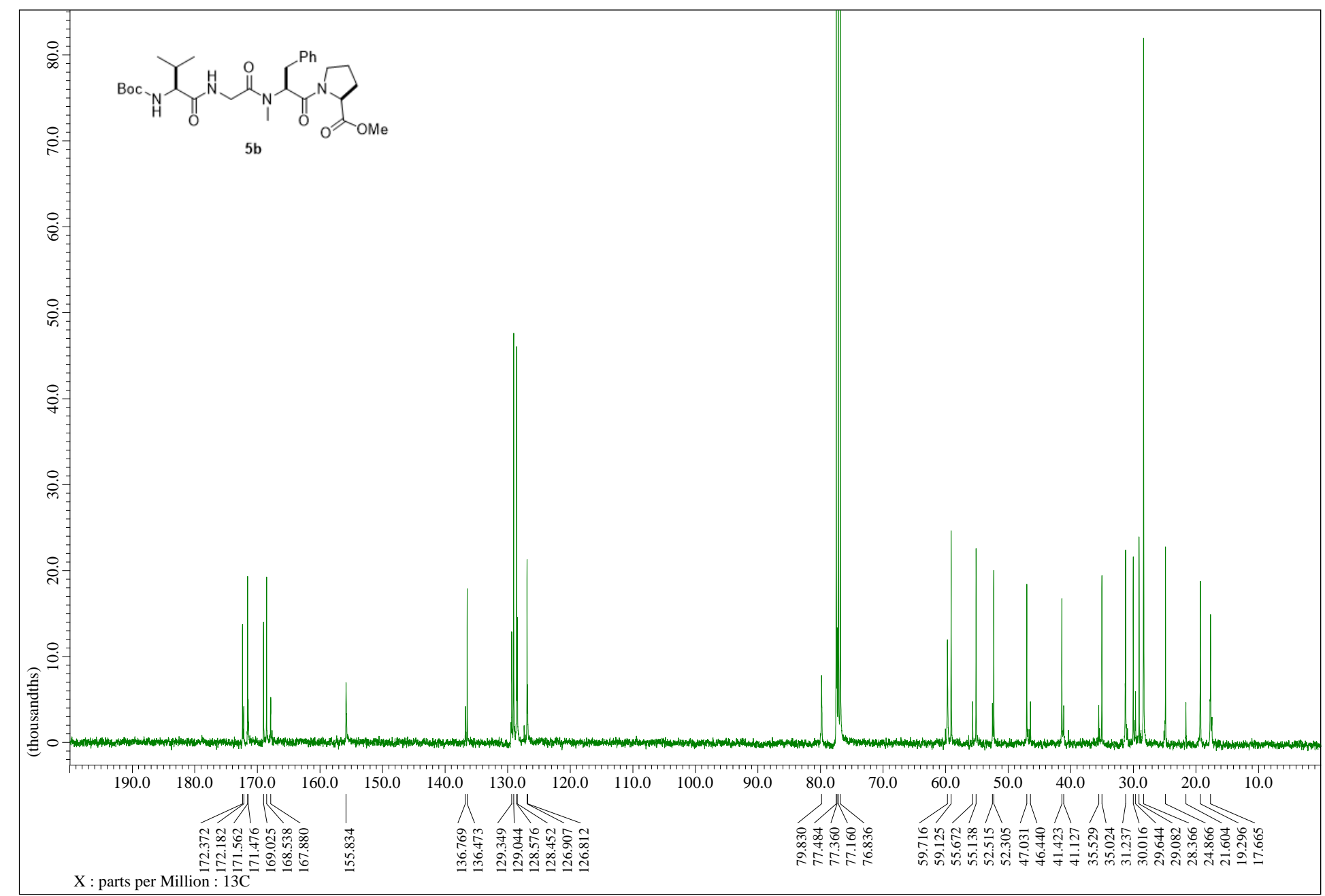

Figure S27. ${ }^{13} \mathrm{C}$ NMR spectrum of tetrapeptide $\mathbf{5 b}$ in $\mathrm{CDCl}_{3}(100 \mathrm{MHz})$ 


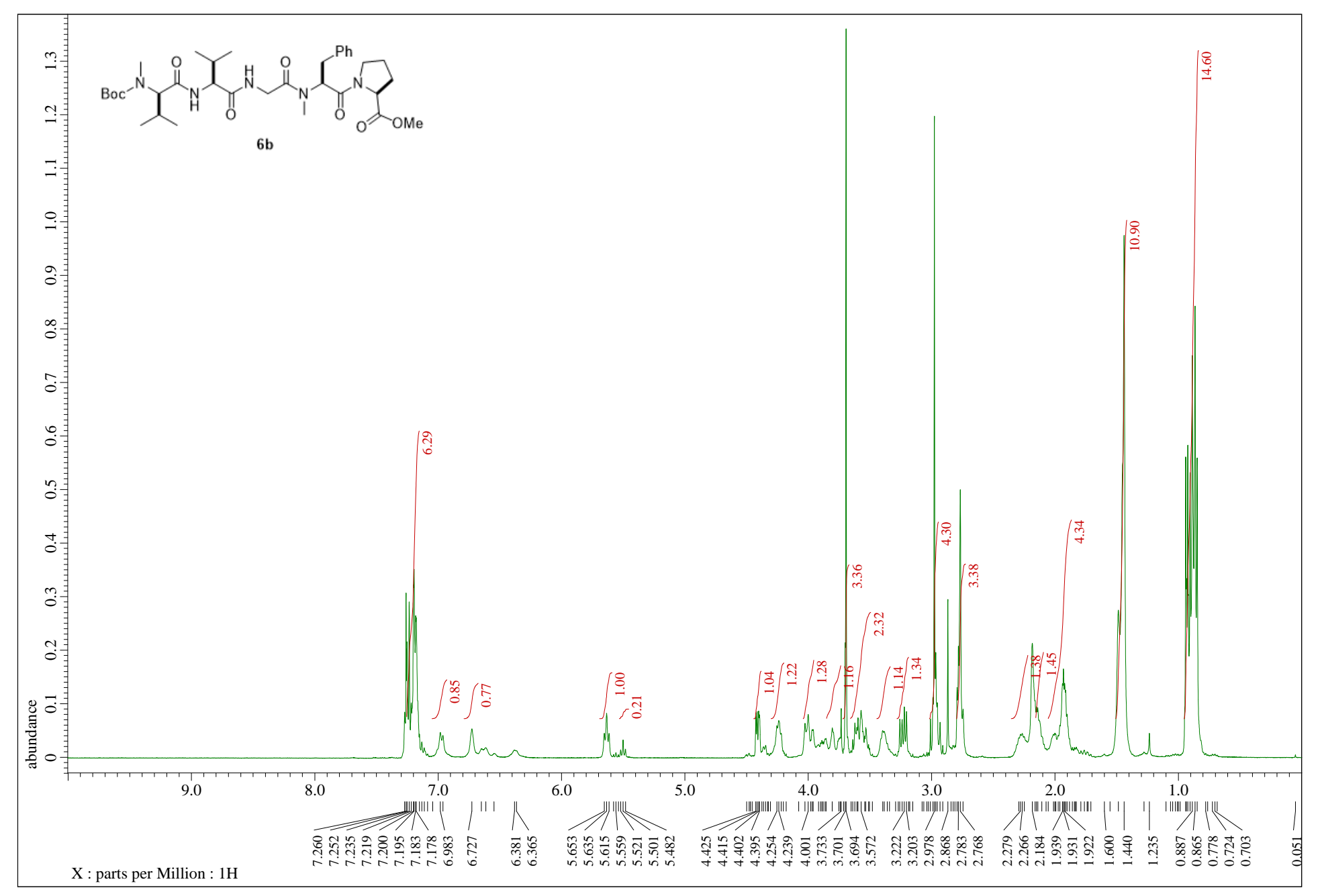

Figure S28. ${ }^{1} \mathrm{H}$ NMR spectrum of pentapeptide $\mathbf{6} \mathbf{b}$ in $\mathrm{CDCl}_{3}(400 \mathrm{MHz})$ 


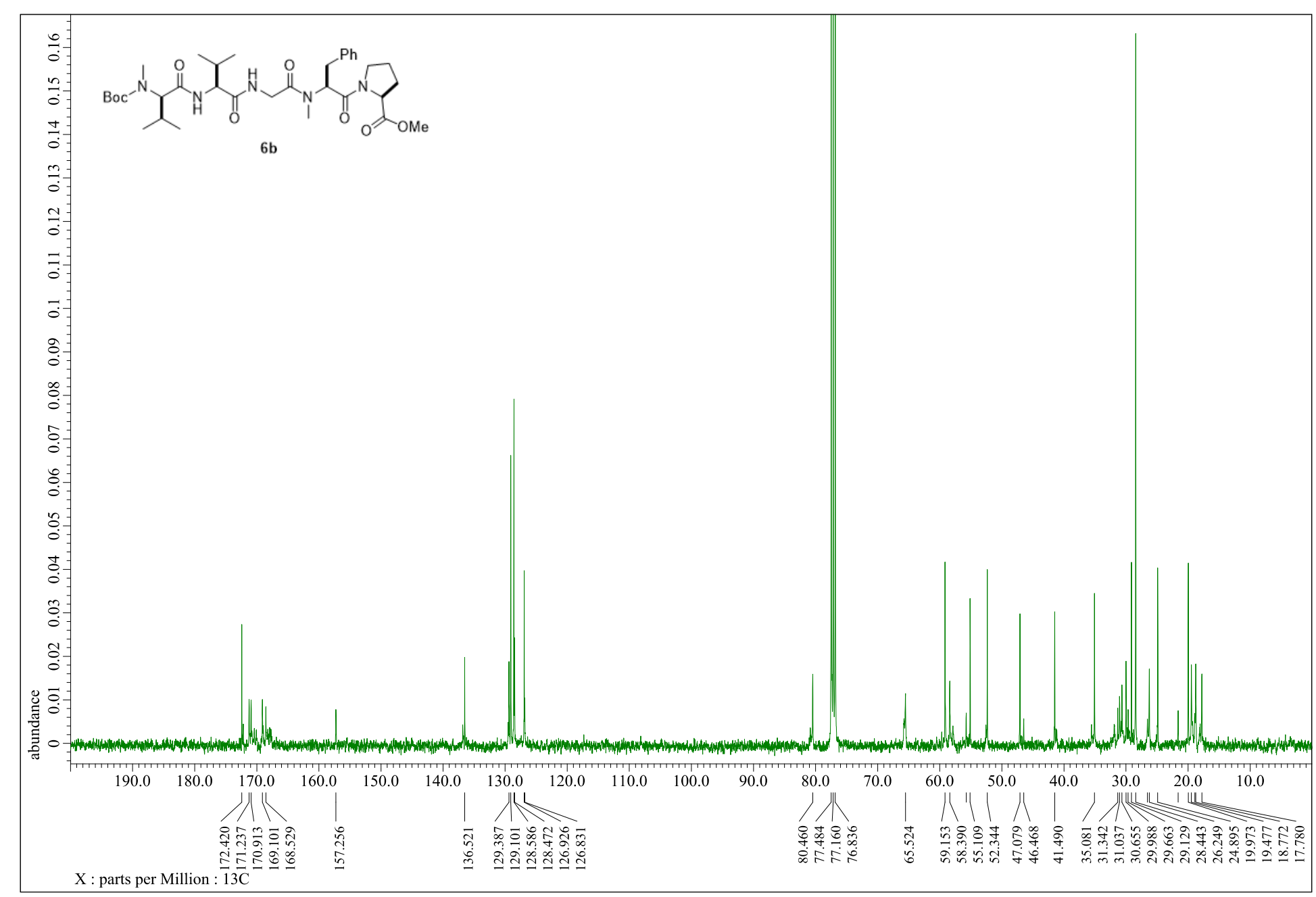

Figure S29. ${ }^{13} \mathrm{C}$ NMR spectrum of pentapeptide $\mathbf{6 b}$ in $\mathrm{CDCl}_{3}(100 \mathrm{MHz})$ 


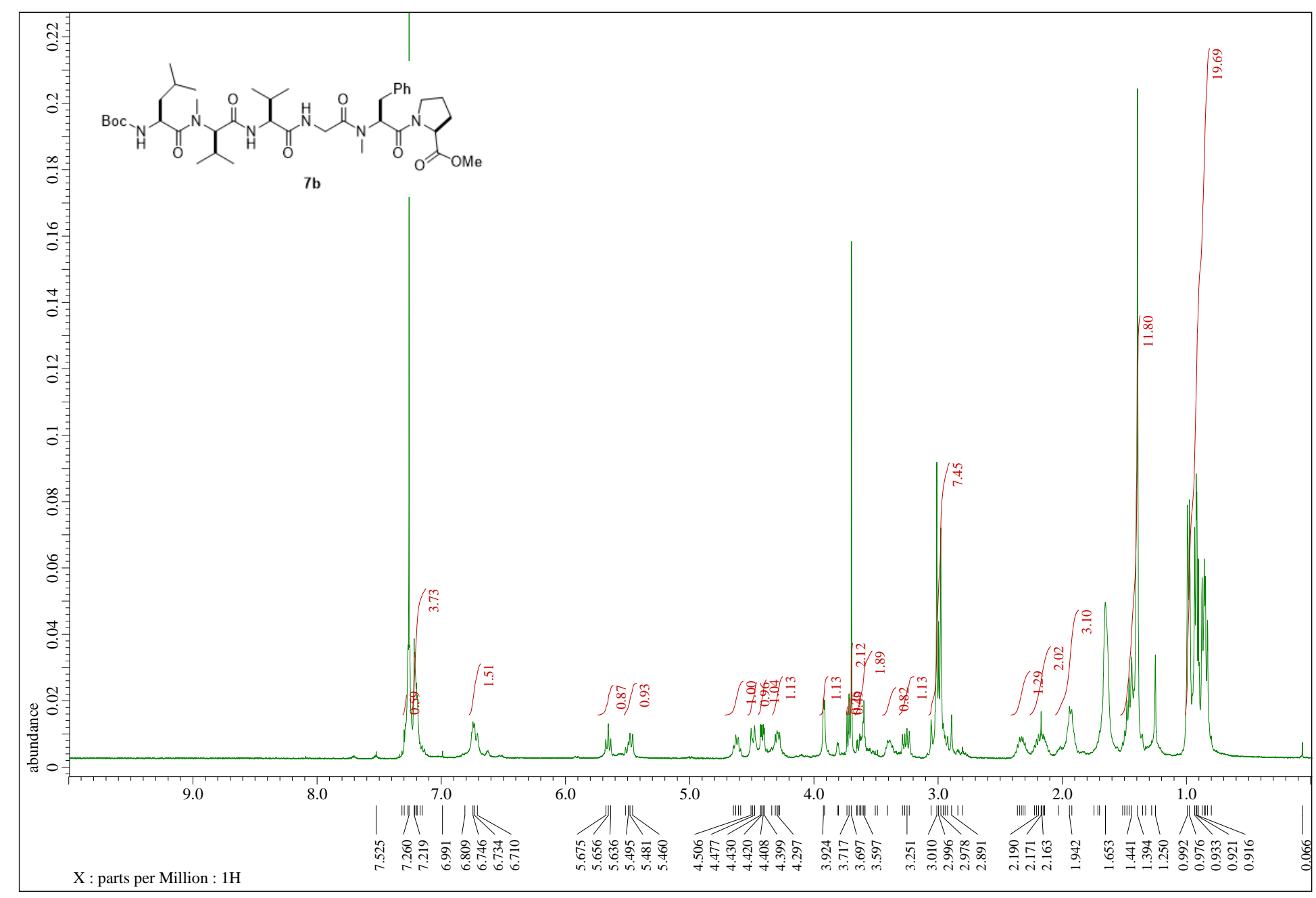

Figure S30. ${ }^{1} \mathrm{H}$ NMR spectrum of hexapeptide $7 \mathbf{b}$ in $\mathrm{CDCl}_{3}(400 \mathrm{MHz})$ 


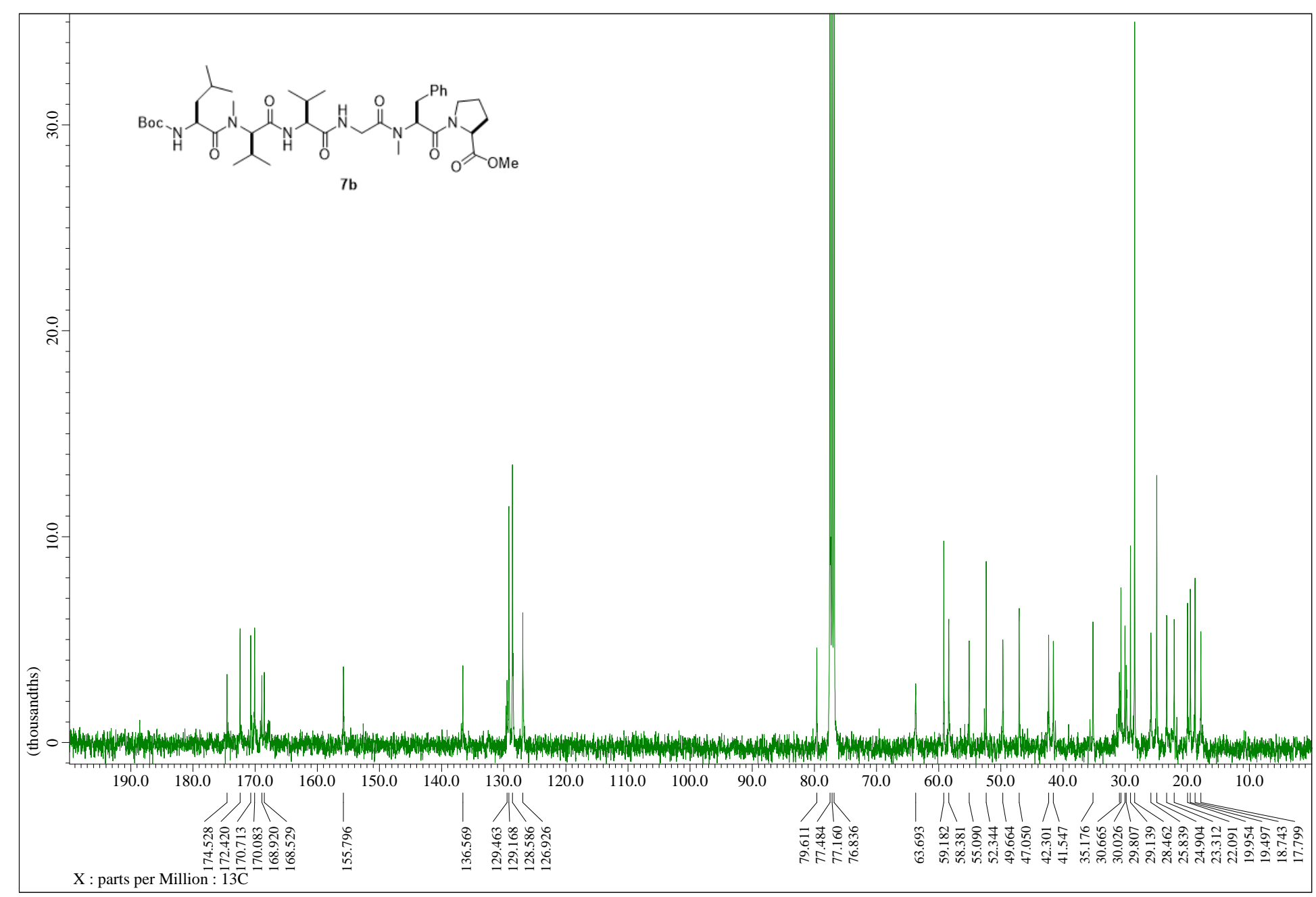

Figure S31. ${ }^{13} \mathrm{C}$ NMR spectrum of hexapeptide $7 \mathbf{b}$ in $\mathrm{CDCl}_{3}(100 \mathrm{MHz})$ 


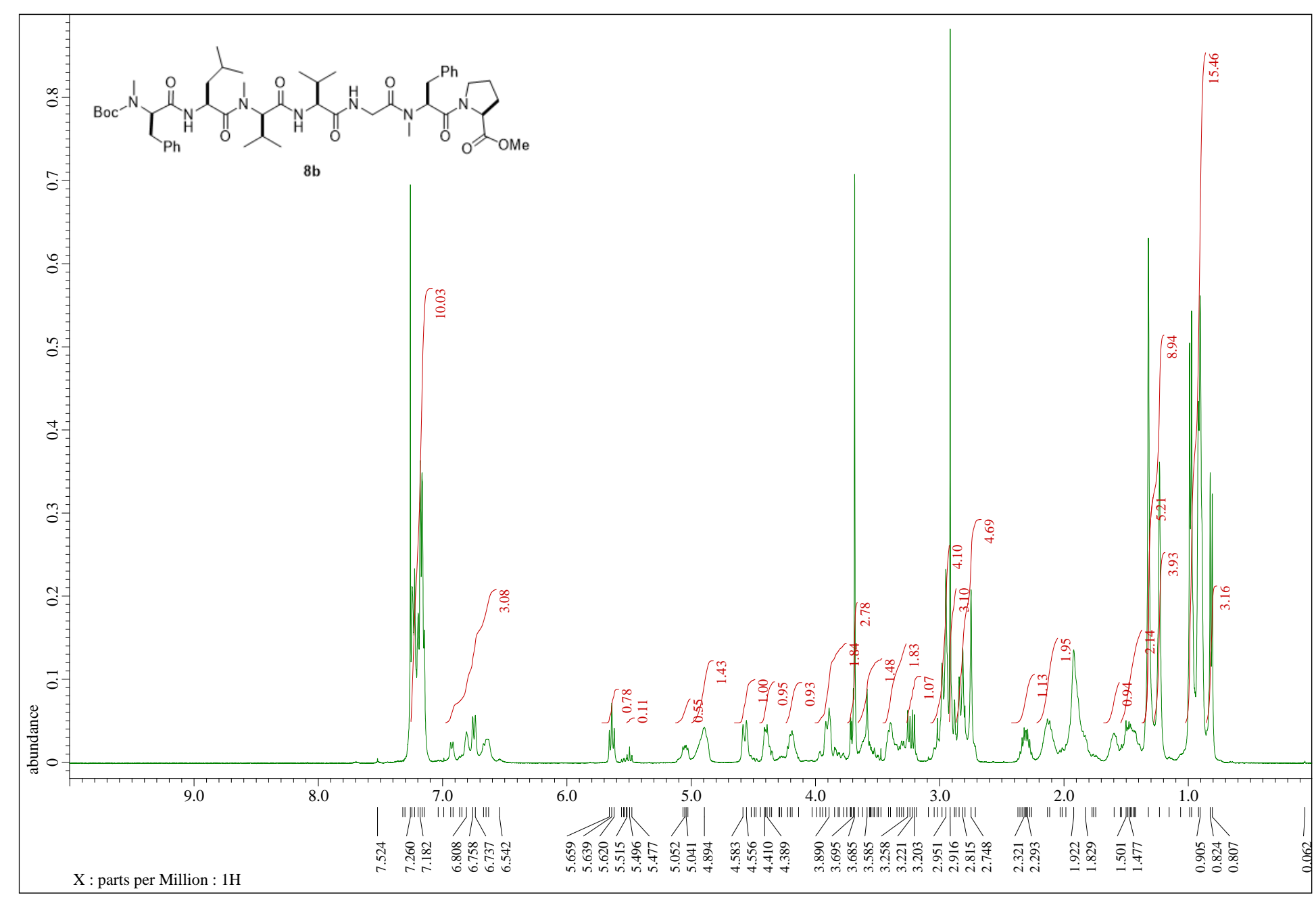

Figure S32. ${ }^{1} \mathrm{H}$ NMR spectrum of heptapeptide $\mathbf{8 b}$ in $\mathrm{CDCl}_{3}(400 \mathrm{MHz})$ 


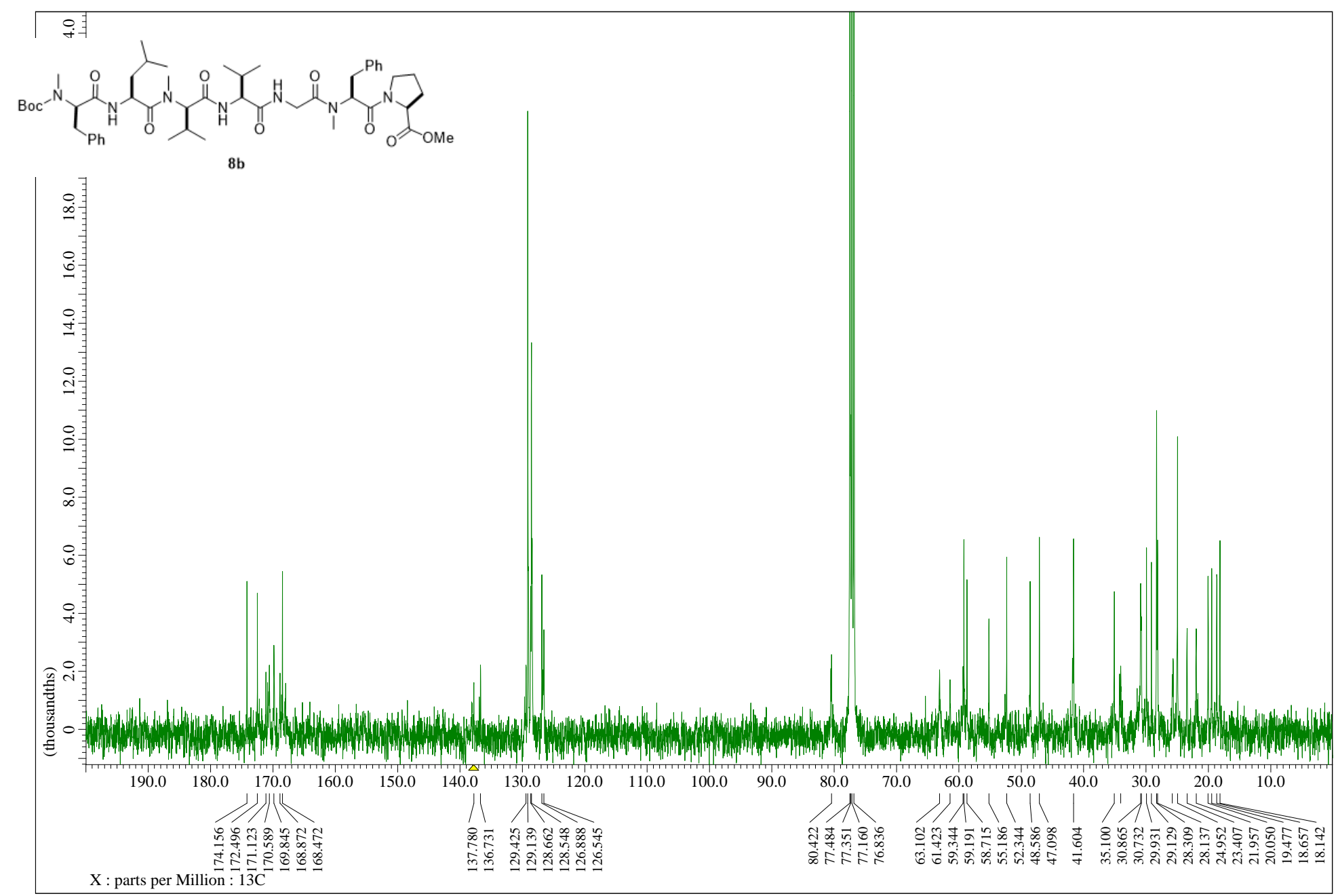

Figure S33. ${ }^{13} \mathrm{C}$ NMR spectrum of heptapeptide $\mathbf{8 b}$ in $\mathrm{CDCl}_{3}(100 \mathrm{MHz})$ 


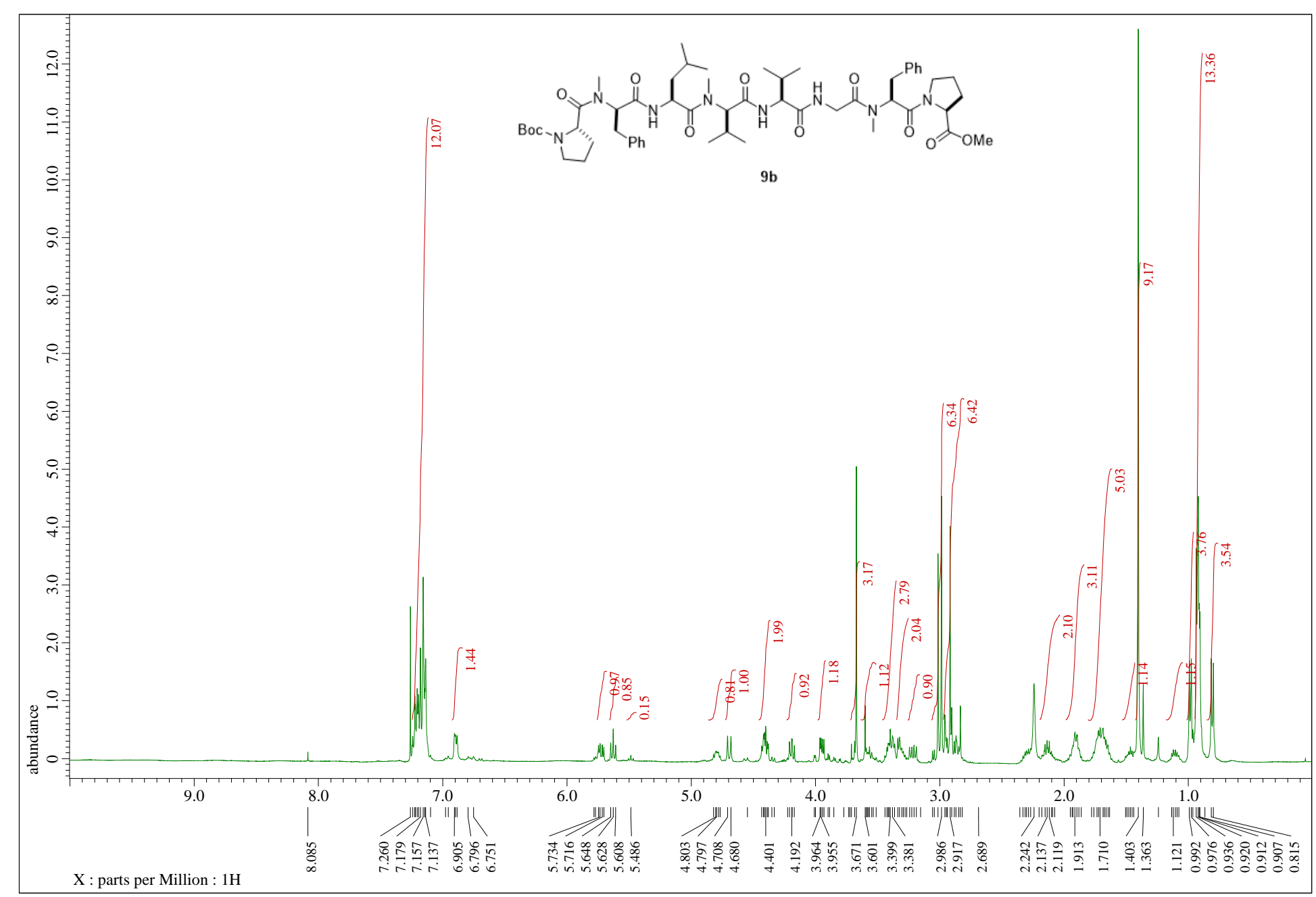

Figure S34. ${ }^{1} \mathrm{H}$ NMR spectrum of octapeptide $9 \mathbf{b}$ in $\mathrm{CDCl}_{3}(400 \mathrm{MHz})$ 


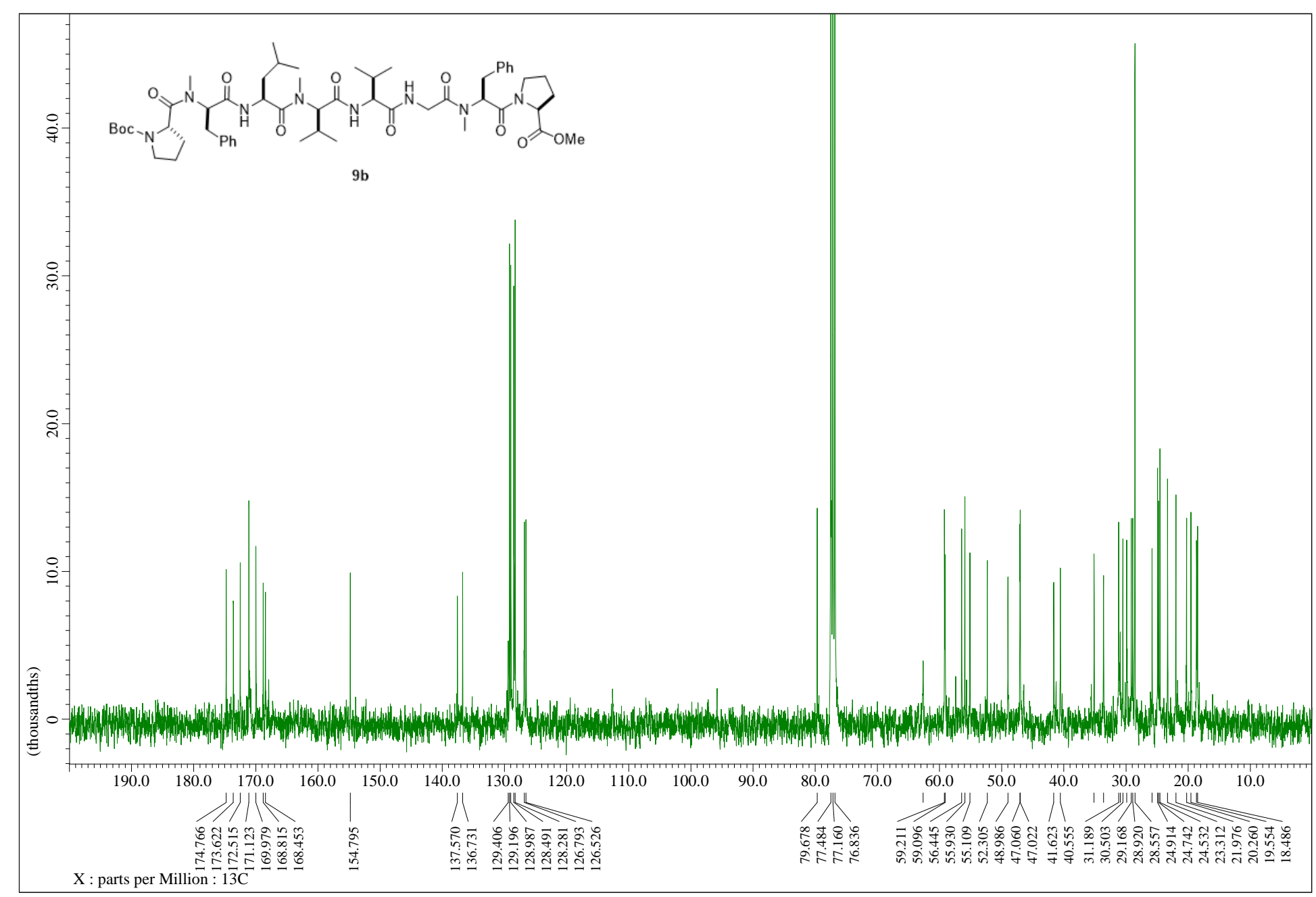

Figure S35. ${ }^{13} \mathrm{C}$ NMR spectrum of octapeptide $9 \mathbf{b}$ in $\mathrm{CDCl}_{3}(100 \mathrm{MHz})$ 


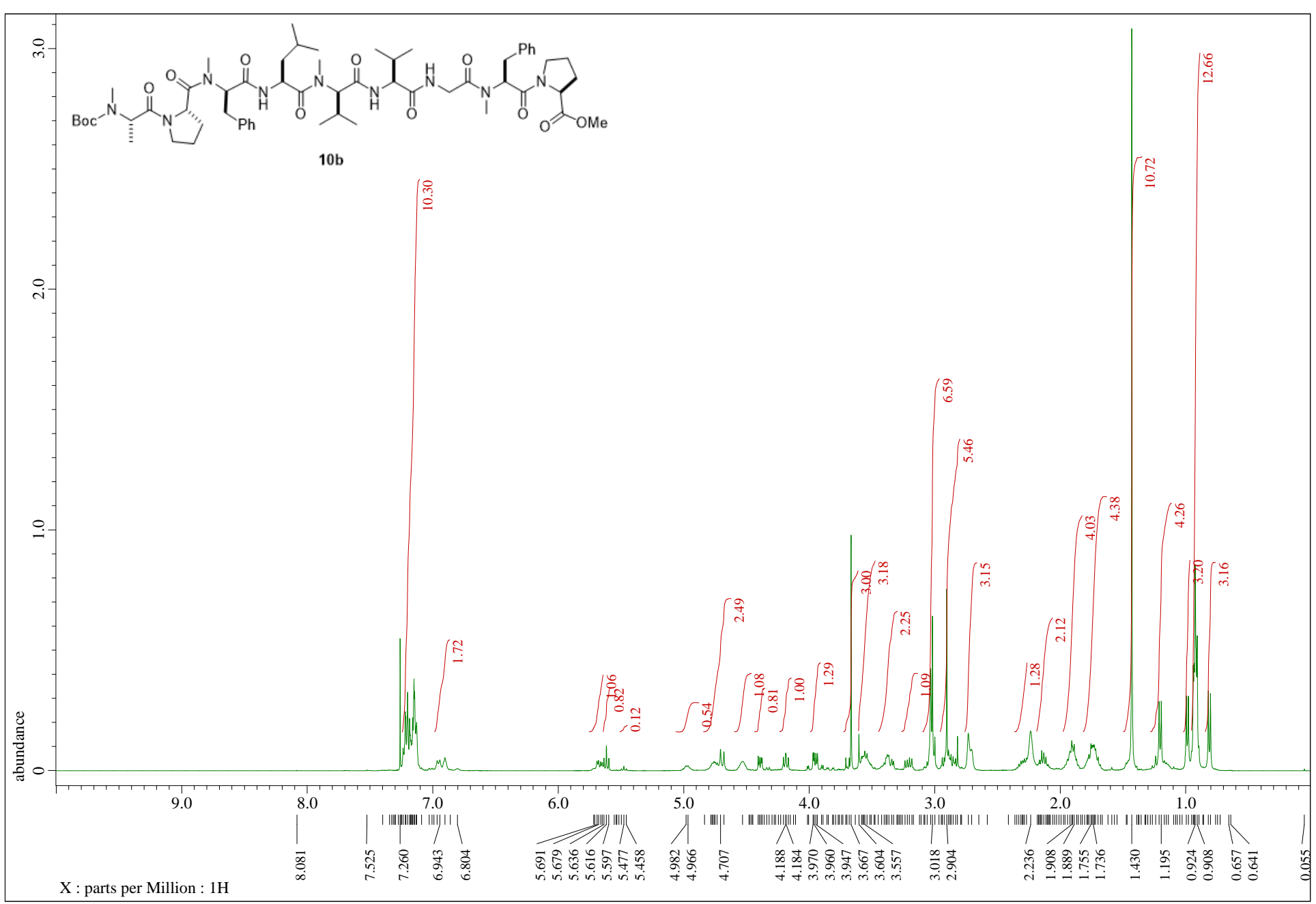

Figure S36. ${ }^{1} \mathrm{H}$ NMR spectrum of nonapeptide $\mathbf{1 0 b}$ in $\mathrm{CDCl}_{3}(400 \mathrm{MHz})$ 


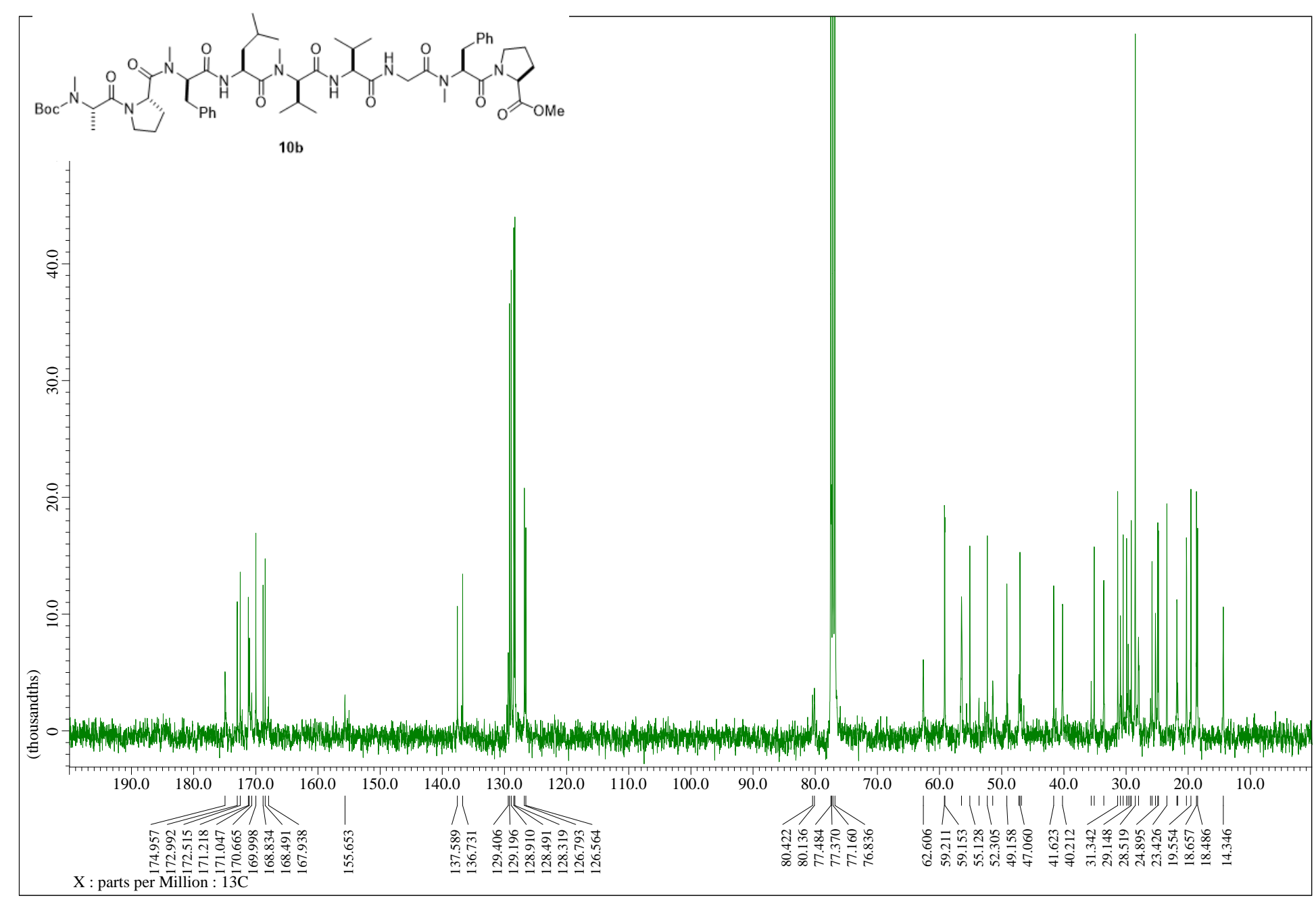

Figure S37. ${ }^{13} \mathrm{C}$ NMR spectrum of nonapeptide $10 b$ in $\mathrm{CDCl}_{3}(100 \mathrm{MHz})$ 


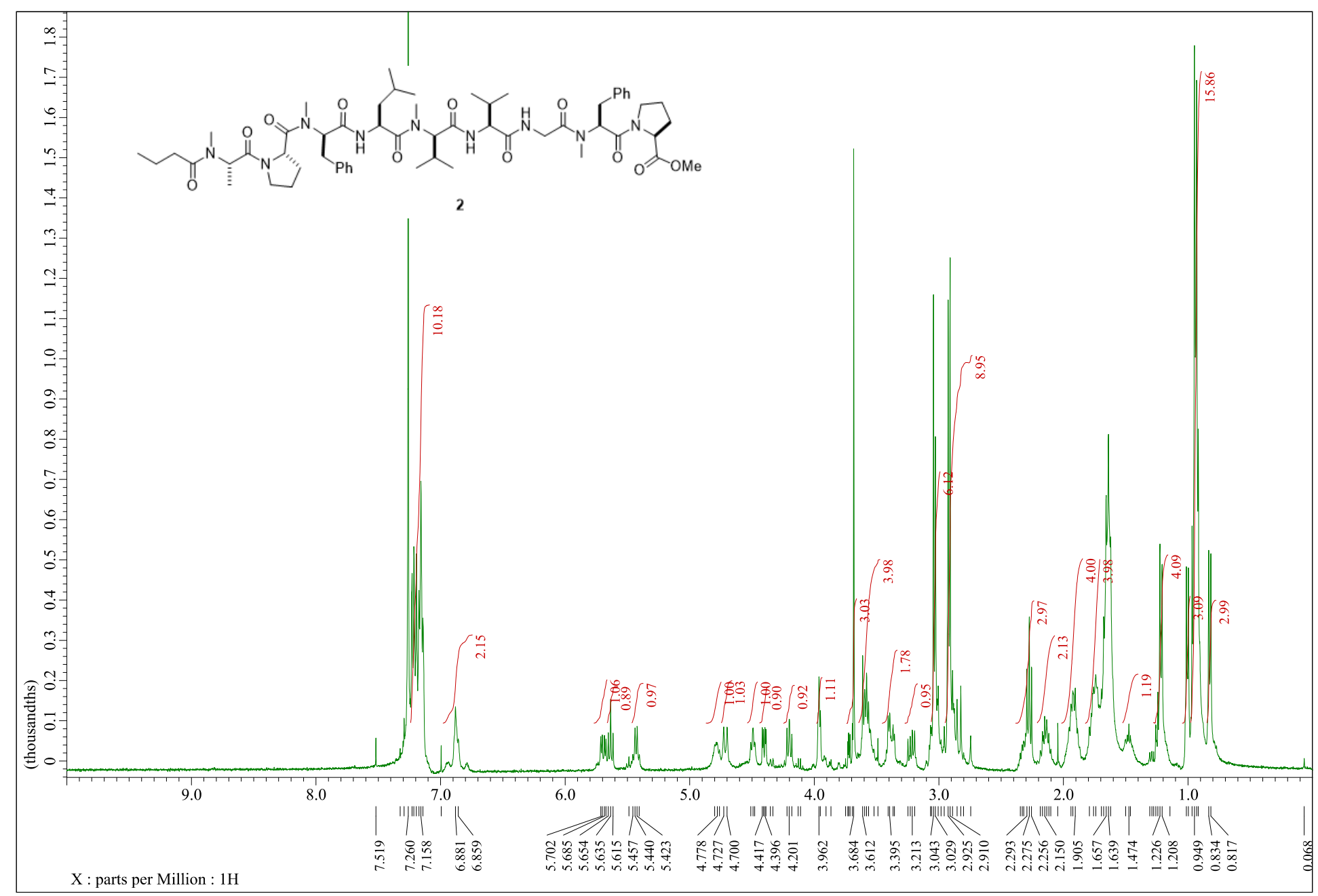

Figure S38. ${ }^{1} \mathrm{H}$ NMR spectrum of iso-mabuniamide (2) in $\mathrm{CDCl}_{3}(400 \mathrm{MHz})$ 


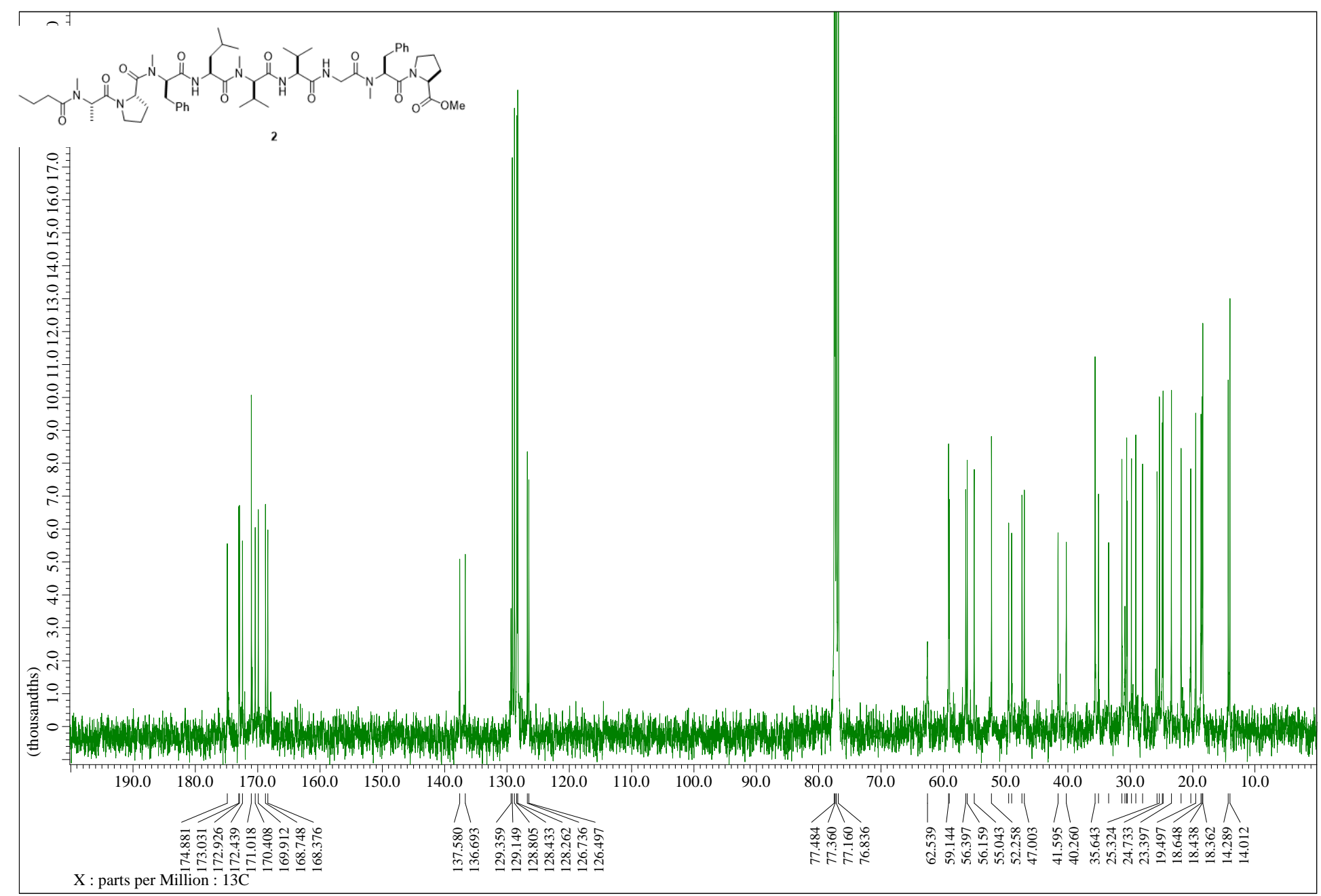

Figure S39. ${ }^{13} \mathrm{C}$ NMR spectrum of iso-mabuniamide (2) in $\mathrm{CDCl}_{3}(100 \mathrm{MHz})$ 


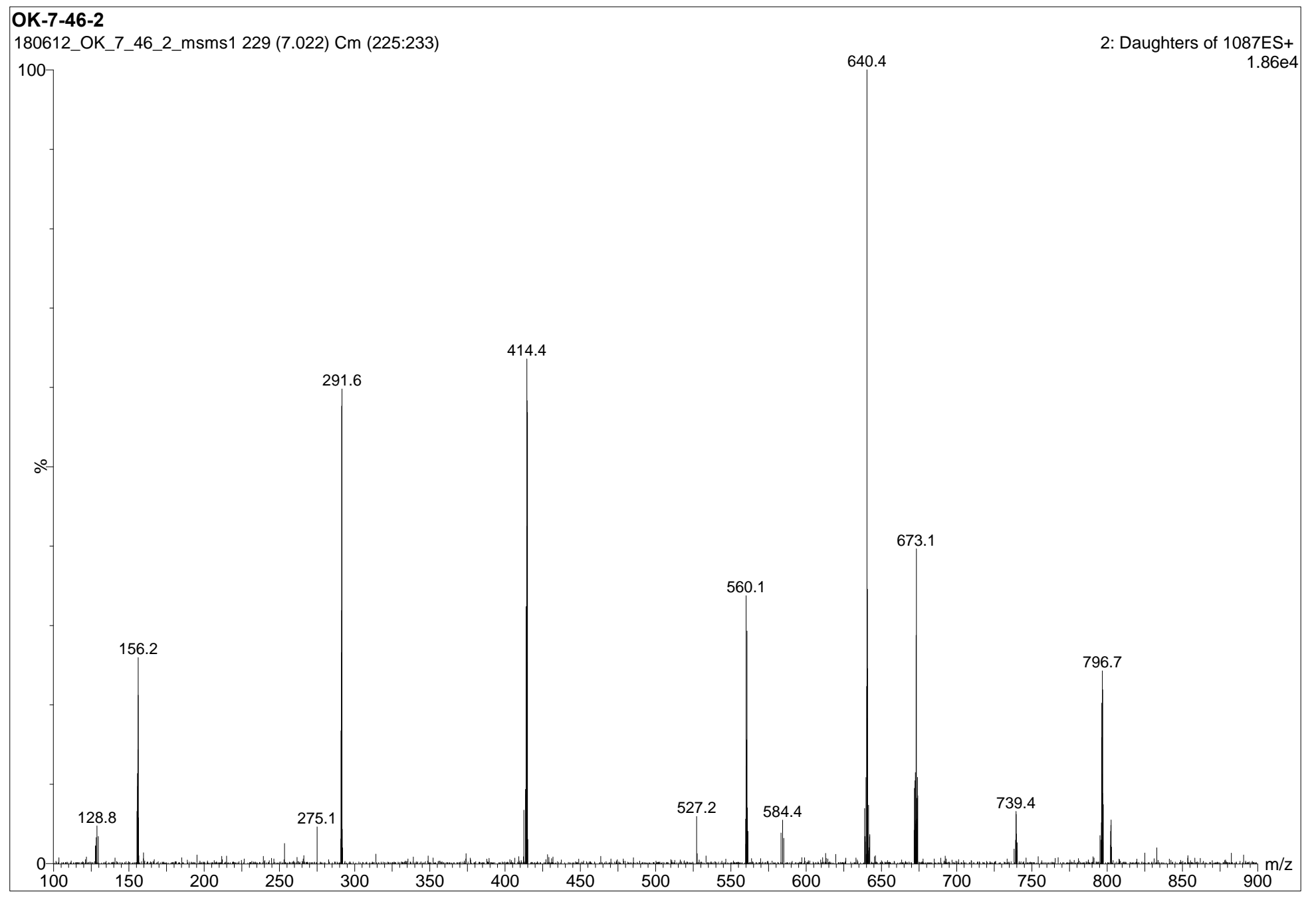

Figure S40. Partial spectrum of MS/MS analysis of mabuniamide (1) 


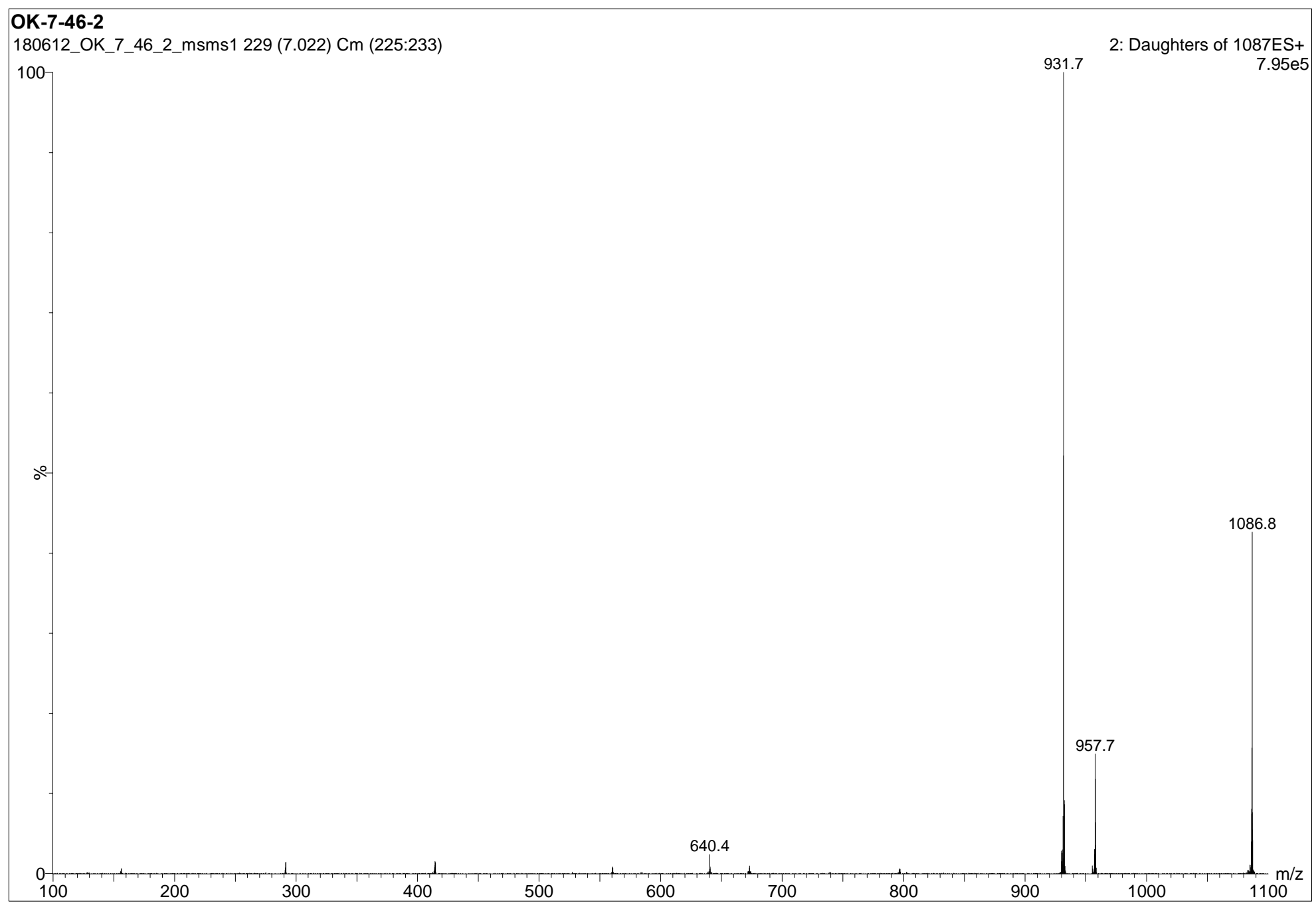

Figure S41. Full spectrum of MS/MS analysis of mabuniamide (1) 